\title{
The Coevolution of Life and Environment on Mars: An Ecosystem Perspective on the Robotic Exploration of Biosignatures
}

\author{
Nathalie A. Cabrol
}

\begin{abstract}
Earth's biological and environmental evolution are intertwined and inseparable. This coevolution has become a fundamental concept in astrobiology and is key to the search for life beyond our planet. In the case of Mars, whether a coevolution took place is unknown, but analyzing the factors at play shows the uniqueness of each planetary experiment regardless of similarities. Early Earth and early Mars shared traits. However, biological processes on Mars, if any, would have had to proceed within the distinctive context of an irreversible atmospheric collapse, greater climate variability, and specific planetary characteristics. In that, Mars is an important test bed for comparing the effects of a unique set of spatiotemporal changes on an Earth-like, yet different, planet. Many questions remain unanswered about Mars' early environment. Nevertheless, existing data sets provide a foundation for an intellectual framework where notional coevolution models can be explored. In this framework, the focus is shifted from planetary-scale habitability to the prospect of habitats, microbial ecotones, pathways to biological dispersal, biomass repositories, and their meaning for exploration. Critically, as we search for biosignatures, this focus demonstrates the importance of starting to think of early Mars as a biosphere and vigorously integrating an ecosystem approach to landing site selection and exploration. Key Words: Astrobiology-Biosignatures-Coevolution of Earth and life-Mars. Astrobiology 18, 1-27.
\end{abstract}

\section{Introduction}

B Y THE END OF THIS DECADE, missions will set out to search for biosignatures on Mars (e.g., Meyer and Schulte, 2014; Beegle et al., 2016; Vago et al., 2006, 2017). Yet despite major advances in our understanding of the red planet, the intellectual framework underpinning this new chapter of exploration remains fundamentally the same as the one that guided the characterization of Mars' habitability (e.g., Mustard et al., 2013). Meanwhile, knowledge gaps about the sustainability of habitable conditions (e.g., Ehlmann et al., 2016) severely constrain our ability to evaluate Mars' past and present ecological potential and the possible interactions between environment and life. Critically, these gaps alter our perspective on key questions, such as where, what, and how to search for biosignatures.

These questions are foundational to all exploration. On Mars, they guide science operations and structure the landing site selection process. For Mars 2020 and ExoMars, candidate landing sites must demonstrate physical characteristics con- sistent with past habitability for early life as we know it, and favorable conditions for the preservation of biosignatures (e.g., Mustard et al., 2013; Vago et al., 2017), along with meeting safety and accessibility criteria. However, implicit assumptions underlie this approach.

One assumption relates to an origin of life and its similarity with terrestrial biology. Past habitability (e.g., Knoll et al., 2005; Des Marais, 2010; Grotzinger et al., 2015a, 2015b) and the discovery of organic chemistry (e.g., Chastain and Chevrier, 2007; Mumma et al., 2009; Freissinet et al., 2015; Webster et al., 2015) make this assumption a viable working hypothesis, and while organic molecules can form from cosmic and geological processes, biology cannot be ruled out (e.g., Mumma et al., 2009; Blamey et al., 2015).

The other assumption relates to biosignatures (e.g., Summons et al., 2011; Hays et al., 2017), which in addition to preservation potential would require that life would have evolved locally or migrated to the proposed sites from its environments of origin. However, causality in this case is not straightforward and currently is strictly inferred from early

The SETI Institute Carl Sagan Center, Mountain View, California.

(C) Nathalie A. Cabrol, 2018; Published by Mary Ann Liebert, Inc. This Open Access article is distributed under the terms of the Creative Commons Attribution Noncommercial License (http://creativecommons.org/licenses/by-nc/4.0/) which permits any noncommercial use, distribution, and reproduction in any medium, provided the original author(s) and the source are credited. 
Earth's environmental history. In effect, the mechanisms or processes by which the early martian environment might have allowed life to evolve and/or migrate from its points of origin to new habitats, that is, biological dispersal (e.g., Nemergut et al., 2013), are barely acknowledged in current exploration strategy or planning, either theoretically or logistically. Early life's evolution on Earth points toward dispersal pathways intimately connected with all aspects of the environment and interactions engaging the lithosphere (including geography and plate tectonics), the atmosphere, the hydrosphere, and their spatiotemporal changes (e.g., Womack et al., 2010; Clobert et al., 2012; Buoro and Carlson, 2014).

On Mars, it is unknown whether life arose (e.g., Jakosky and Shock, 1998; Brack et al., 1999; Brack, 2000; Schulze-Makuch et al., 2005; Jepsen et al., 2007; McKay, 2010; Cockell et al., 2012; Westall et al., 2013; Retallack, 2014; Levin and Straat, 2016; Catling and Kasting, 2017). But if it did, it is expected that the planet's own specific characteristics and environment (e.g., the global dichotomy, tectonic style-two-plate planet or no plate tectonics, and the debated existence of oceans) would have played an equally important, if not overarching, role in the origin and evolution of any indigenous biology; and while early Mars was Earth-like, it was never exactly like Earth.

How much these differences would have affected the evolution of an early biosphere and subsequent dispersal pathways has yet to be evaluated, but as we embark on a search for biosignatures, our vision is still very much anchored in a reductionist approach, where diverse data sets are juxtaposed in snapshots defined by their geological ages. What has yet to happen is to think of Mars in terms of a possible coevolution of life and environment, where data are synergistically pulled together in a dynamic vision of an ecosystem. The merit of such a perspective is to give consideration to what the characteristics of an early martian biosphere, if any, would have been like. Performing this exercise to the best of our knowledge, as limited as it may be today, is not only important at this stage but necessary to the development of a more systemic, substantive, and informed guiding principle about where to search (potential exploration sites), what to search for (types of habitats and biosignatures), and how to explore (scales, resolution, instruments, and detection thresholds).

A number of studies have envisioned spatiotemporal scenarios that lead to the definition of habitable environments, microorganisms, metabolisms, and plausible fossil records on Mars (e.g., McKay and Stoker, 1989; Brack et al., 1999; Fairén et al., 2005, 2010; Schulze-Makuch et al., 2005, 2008; Anand et al., 2006; Knoll and Grotzinger, 2006; Gómez et al., 2012; Westall et al., 2013; Davila and Schulze-Makuch, 2016; Ehlmann et al., 2016). Here, we center the focus on environmental pathways through which life could have dispersed over time on Mars and their significance for biomass repositories and biosignature exploration.

In the following sections, we examine Mars through the lens of the coevolution of life and environment as we understand it from early Earth (Fig. 1). We first consider how spatiotemporal scales and spectral resolution affect our perception of this synergy, but also how they generate some confusion between the notions of planetary habitability and habitat, which in turn affects our perspective on detection thresholds. Then, we explore hypothetical concepts of coevolution, where the factors of a coevolution include what is known today of life's origin and early habitats on Earth—and their timing_-projected within the

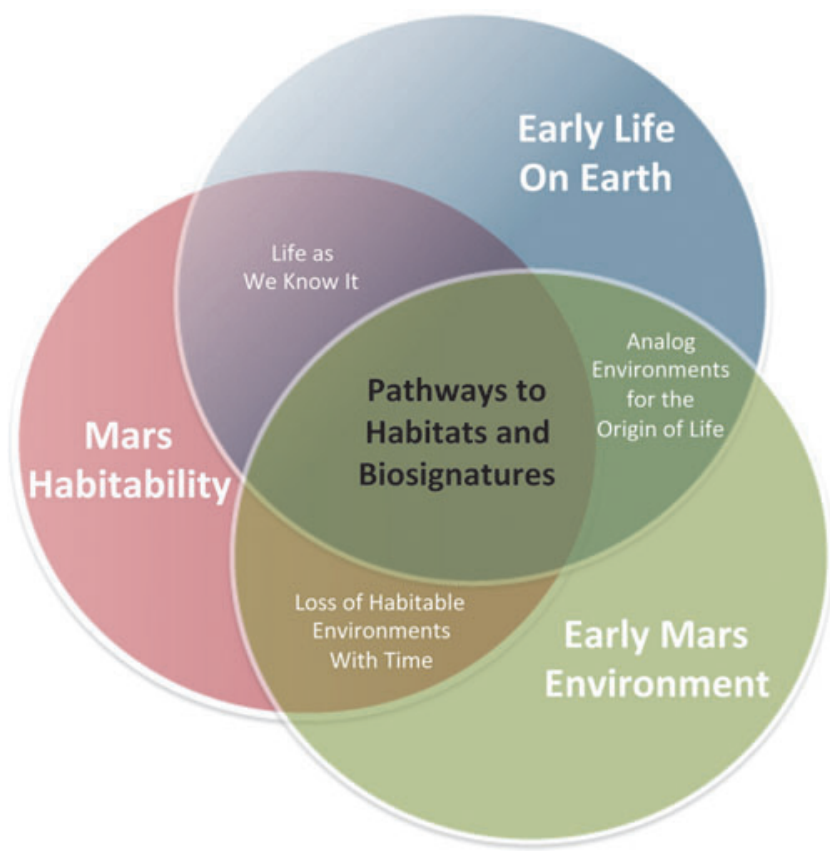

FIG. 1. Framework for a coevolution on Marsuncertainties about the origin(s) of life on Earth and the early martian environment, and the use of Earth's chronology for early life in the context of Mars, limit any notional coevolution model. Here, the variables are the plausible environments of origin(s) for life on Mars in view of terrestrial theories and what is known of the evolution of habitability on Mars. The fix parameter is life as we know it, with the chronology provided by discoveries made on Earth to date. We assume a timing for the earliest evidence of life consistent with Earth at $4.28 \mathrm{Ga}$ (references in the text) and focus on early life colonization and dispersal pathways from these environments of origin.

distinct environmental and physical evolution of early Mars. This approach considers the recent results from the Mars Atmosphere and Volatile EvolutioN (MAVEN) mission (e.g., Jakosky et al., 2017) and new evidence that Mars was volcanically active well into the Late Amazonian (references herein). From this comparison, a broad ecological framework emerges, which includes blueprints for early habitats and plausible dispersal pathways. Among the pathways identified, some suggest that differences between the two planets may not have mattered in the first several hundred million years, whereas other pathways would have exposed early life to the pressure of a rapidly declining planetary habitability. Yet others may have sheltered and, thus, sustained life since its origin despite surface changes. All have implications for the distribution and preservation of biosignatures. The final section is, therefore, devoted to science focus, detection thresholds, and exploration strategies.

\section{The Three Earths and the Three Mars}

Environmental changes have accompanied life since its inception on Earth either as causes or effects (e.g., Knoll, 2009). Assuming life is active, and/or biosignatures preserved, any planet or moon that develops a biosphere will bear the signatures of its own coevolution as embedded data that sum up all the synergies between life and environment since their formation, and their relative dominance over 
time. This information may be neither obvious nor equally accessible from one world to the next. Our perception of these synergies is driven by the spatiotemporal scales and resolution used to examine them, and by whether they are analyzed holistically or as discrete sets of variables. Depending on the prism through which we observe them, they either reveal a complex continuum or only tipping points.

For instance, over geological scales and at low spatiotemporal resolution, Earth may be compared to a multitude of distinct planets, alternatively showing similarities with water worlds recently discovered (e.g., Burnham and Berry, 2017): Titan (e.g., Trainer et al., 2006) or Enceladus (e.g., Kargel, 2006). Similarly, the biological Earth can be roughly reduced to three different planets: the prokaryotic Earth of the Archean $(>2.5 \mathrm{Ga})$, the eukaryotic Earth of the Proterozoic (2.5-0.542 Ga), or the Cambrian Earth $(<0.542$ $\mathrm{Ga}$ ) with the rise of most major animal phyla.

Although accurate, this reductionist view of Earth's environmental or biological evolution is essentially a caricature, a series of snapshots that gives little information on how these Earths, apparently so distinct from each other, are in fact woven seamlessly together through coevolution. One planetary environment leads to the next through uninterrupted internal feedback loops and external forcing, where every single moment combines all the systemic history that preceded. Comprehending the spatiotemporal complexity of the coevolution of life and environment (i.e., what makes a planet or an environment habitable); how habitats are created and transformed over time; and how life adapts, survives, and changes its environment requires the integration of multiscale data sets from a diversity of scientific fields and an understanding of their relative significance. Obviously, the more gaps in the data, the more difficult the reconstruction of this complexity becomes, and in essence, beyond Earth, this is the primary challenge faced by planetary exploration.

The exploration of Mars best exemplifies this issue. Over the past decades, an integrated program of missions has characterized its geological evolution (e.g., Albee et al., 2001; Chicarro, 2006), past and present climate (e.g., Inada et al., 2007; Jakosky et al., 2017), and ancient habitable environments (e.g., Knoll et al., 2005; Des Marais, 2010; Grotzinger, 2014; Grotzinger et al., 2014). Searching for biosignatures is thus a next logical step, but transitioning from the characterization of ancient habitable conditions to the search for biosignatures requires that, accordingly, we shift the focus of exploration from planetary habitability to the identification of habitats. Although these two notions are often confused outside ecology, they are fundamentally distinct. Habitability designates the general conditions favorable to life at local to global scales (e.g., water, energy, nutrients, shelter), whereas habitats are defined by their inhabitants and, for Mars, focus on potential microorganisms and their spatiotemporal dynamics.

Searching for early signs of life on Mars may involve, at best, the equivalent of exploring the Archean record (e.g., Farmer and Des Marais, 1999; Cady et al., 2003; Schopf, 2006; Summons et al., 2011) with an understanding of the early environment that remains elementary and fundamental questions that are unanswered (e.g., Ehlmann et al., 2016). This understanding relies chiefly on orbital data with spectral range and spatial resolution that have allowed the identification of three distinct geological periods on Mars based on dominant mineral alterations: the Phyllocian (4.5-4.0 Ga), Theiikian (4.0-3.5 Ga), and Siderikan (3.5 Ga to present) (Bibring et al., 2005, 2006). This timescale broadly overlaps with that of impact crater densities and major geological and environmental changes (e.g., Tanaka, 1986), including the Noachian $(4.1-3.7 \mathrm{Ga})$, which is characterized by the heavy bombardment and valley network formation; the Hesperian (3.7-3.1 Ga), which gave rise to increasing aridity, intense volcanism, the formation of outflows, and possibly an ocean; and the Amazonian (3.1 Ga to the present), a time when Mars became the planet we observe today, with residual flood, glacial, and volcanic activity.

In addition to these geological periods, Pre-Noachian Mars (4.5-4.1 Ga) marks the accretion time, the formation of the global dichotomy, the loss of the magnetic field, and changes in the atmosphere (see Section 3 and references therein). Little record is left of this period (e.g., Frey, 2006), but if the chronology of life's origin and early coevolution on Earth has any bearing on Mars, these events alone make the Pre-Noachian a key period in Mars' history given that it established unique initial conditions for a coevolution.

Our knowledge also relies on high-resolution data acquired at Gusev and Gale Craters and Meridiani Planum. From an environmental standpoint, these data are consistent from one site to the next and support the view of a globally declining habitability. In contrast, because of this decline, extrapolating about microbial habitats at scales broader than the individual site should be done carefully, while considering the age of the site and the potential interactions between habitats and environment (e.g., surface, subsurface, deep underground). Within 700 million years of accretion, the surface of Mars had become hostile for life as we know it (e.g., Jakosky et al., 2017), and terrestrial analogues show that local (meter to micrometer scale), not global, factors dominate the evolution of microbial habitats in such environments (e.g., Amils et al., 2007; Cabrol et al., 2007a; Warren-Rhodes et al., 2007a, 2007b; Preston and Dartnell, 2014); see Sections 4-6.

Through the current low-resolution prism, our vision of the evolution of Mars is thus as much of a caricature as the three Earths. As a result, the intellectual framework guiding the search for biosignatures suffers from an internal conflict, whereby the scientific focus (mission goal) is lost to background noise (insufficient data resolution), and the important details (framed hypotheses on microbial ecosystems) are lost to generalization (planetary habitability). However, if current data are not well adapted to characterize Mars at the microbial habitat level yet, they can still help us articulate science questions about early Mars from a different and ecologically dynamic perspective. Importantly, they can support the development of working models and better decision-making tools on whether the types of sites we deem a priority (e.g., Hays et al., 2017) were likely (or not) to produce habitats and preserve biosignatures in Mars-specific sets of environmental circumstances, that is, rather than simply inferring their potential from a strict terrestrial ecosystem analogy.

Examples of reframed science questions include the following:

(1) What role did environmental differences between Earth and Mars play in an early evolution of life on Mars? (2) What was the impact of the unique physical features (e.g., global dichotomy, high obliquity, lost magnetosphere 
and atmosphere, volcanic and tectonic characteristics) on the formation and spatiotemporal evolution of environmental pathways to biological dispersal? (3) What does a comparison between the timing of early life evolution on Earth and the current environmental models for early Mars suggest about ancient habitable environments, their habitat development potential, biological dispersal, biosignature preservation, and detection thresholds?

The framework defined by these questions allows the exploration of notional models of environmental pathways, which ultimately helps narrow down plausible biomass repositories. The discussion that follows involves geological and environmental thresholds; therefore, the crater density timescale (Noachian, Hesperian, and Amazonian) is being used.

\section{Environments for an Origin of Life}

How we search for life beyond our planet is guided, and possibly limited, by what we know from Earth, and many questions remain unanswered today about the origin(s) of life. Simple organic compounds may have formed (references herein) and/or were delivered by comets and asteroids (e.g., Chyba and Sagan, 1992; Ehrenfreund and Cami, 2010; Zahnle et al., 2010; Santosh et al., 2017). In the Oparin-Haldane hypothesis, life arose gradually from inorganic molecules in a reducing atmosphere where they reacted with lightning and/or the energy of the Sun to produce amino acids and nucleotides. Over time, proteins and nucleic acids formed into selfsustaining biomolecules capable of replicating (e.g., Armstrong and Brasier, 2004). The test of the Oparin-Haldane hypothesis (e.g., Miller and Urey, 1959) demonstrated that at least some of the building blocks of life could form from simple inorganic compounds in a broad range of environments (e.g., Gilbert, 1986; Lazcano and Miller, 1996; Shapiro, 2000; McCollom, 2013).

\subsection{Earth}

Theories about the transition of prebiotic chemistry to biology include environments such as deep sea vents (e.g., Baross and Hoffman, 1985; Shock, 1992; Visscher 1993; Wächtershäuser, 2006; Martin et al., 2008; Sleep, 2010; Nisbet and Fowler, 2013; Dodd et al., 2017) on an ocean planet with a few landmasses only (e.g., Cavosie et al., 2007; Ushikubo et al., 2008; Burnham and Berry, 2017); the surface of the sea (e.g., Michaelian, 2011); tidal pools (e.g., Lasaga et al., 1971; Lahav et al., 1978); hydrothermal systems and hot springs (e.g., Shock 1993; Djokic et al., 2017); mineral-water-air interphases (e.g., Hazen, 2012; Yang et al., 2013); and volcanic aquifers (e.g., Washington, 2000). Plate tectonics is viewed as essential to a terrestrial "habitability trinity" defined by the coexistence of ocean, landmass, and atmosphere (e.g., Bercovici and Ricard, 2014; Dohm and Maruyama, 2015; Azuma et al., 2017). It controls rock cycling; the formation and destruction of continents; and the impact of these processes on mineral systems, the environment, and the production of nutrients for life (e.g., Maruyama et al., 2007; Santosh, 2010; Pirajno, 2015; Santosh et al., 2017). Exactly when plate tectonics started is debated (e.g., Condie and Kröner, 2008), with estimates ranging from the early Neoproterozoic (e.g., Stern, 2005) to soon after the formation of the primordial ocean in the Hadean (e.g., Korenaga, 2013). Nutrients may have been produced on primordial continents on a dry Earth after the solidification of the magma ocean, volatiles accreted through impact processes, and conditions occurred that were conducive to the inception of life between 4.37 and $4.20 \mathrm{Ga}$ (e.g., Santosh et al., 2017).

Until recently, the earliest indirect evidence of biological activity was the 3.8-3.7 Ga old metamorphosed sedimentary rocks and minerals from the Isua supracrustal belt in southwest Greenland (e.g., Van Zuilen et al., 2003; Rosing and Frei, 2004). Biogenic carbon may be present in 4.1 Ga rocks from Jack Hills, Western Australia (e.g., Bell et al., 2015), and biogenic structures as old as $4.28 \mathrm{Ga}$ in ancient oceanic floor material of the Nuvvuagittup supracrustal belt, Canada (e.g., Dodd et al., 2017). Metacarbonate rocks in the Isua supracrustal belt contain stromatolites (e.g., Nutman et al., 2016) that developed in a shallow marine environment $(3.7 \mathrm{Ga})$, predating by 220 million years the oldest fossils of the Dresser Formation in Pilbara, Australia (e.g. Walter et al., 1980; Van Kranendonk, 2011; Noffke et al., 2013). Seafloor hydrothermal vents, shallow marine continental margins, and intertidal environments have thus produced the oldest evidence of early life to date (e.g., Klein et al., 1987; Noffke et al., 2006; Westall et al., 2006; Schopf et al., 2007; Noffke, 2009; Van Kranendonk, 2011). Microfossils, microbialites, isotopic and molecular biomarkers also show that prokaryotic life was abundant in these environments $\sim 3.5-3.4$ Ga (e.g., BeraldiCampesi, 2013). Hot spring pool and vent deposits constitute the earliest evidence $(3.5 \mathrm{Ga})$ of life on land (e.g., Djokic et al., 2017). These biosignatures are close in age to the Strelley Pool fossil record $(3.43 \mathrm{Ga})$ that formed in a shallow sea environment (e.g., Hofmann et al., 1999).

\subsection{Mars}

The nature of the martian climate and environment during the same time frame $(4.3-3.4 \mathrm{Ga})$ is one of the long-standing questions and outstanding issues having a direct bearing on a coevolution (e.g., Ehlmann et al., 2016; Wordsworth, 2016). We summarize in Table 1 (and references therein) the main theories as they relate to the environmental context for our discussion, and refer to recent reviews for more details.

While an origin of life around deep sea vents is a leading theory for Earth, the existence of a Pre-Noachian to early Noachian primordial ocean is still in question due to the scarcity of the geological record (e.g., Carr and Head, 2003; Frey, 2003, 2006). Its existence and extent hinge on climate models, estimates of volatile sources and sinks, disparate global equivalent layer (GEL) values (i.e., the thickness of an amount of water spread evenly over Mars), subpermafrost aquifer modeling, and proposed shorelines in Hellas (see Table 1 and references therein). It is discussed here as a theoretical environmental endmember.

If a primordial ocean was present in the Pre-Noachian, volcanism distributed globally since crustal formation would have supported the development of a pervasive Pre-Noachian subseafloor aquifer heated by magma. Hydrothermal activity would have been widespread, with energy concentrated in the equatorial regions (e.g., Leone et al., 2014, Table 1). Although decreasing over time, this energy remained available for later oceans that formed episodically across the Hesperian and Amazonian (e.g., Baker, 2001; Carr and Head, 2003; Dohm et al., 2009a, 2009b; Luo et al., 2017). Chemicals released in such environments on Earth set up redox reactions, which would have caused electrical currents to flow naturally around 
Table 1. Mars Early Evolution-Earth-Like, But... (Almost) All Things Being Unequal

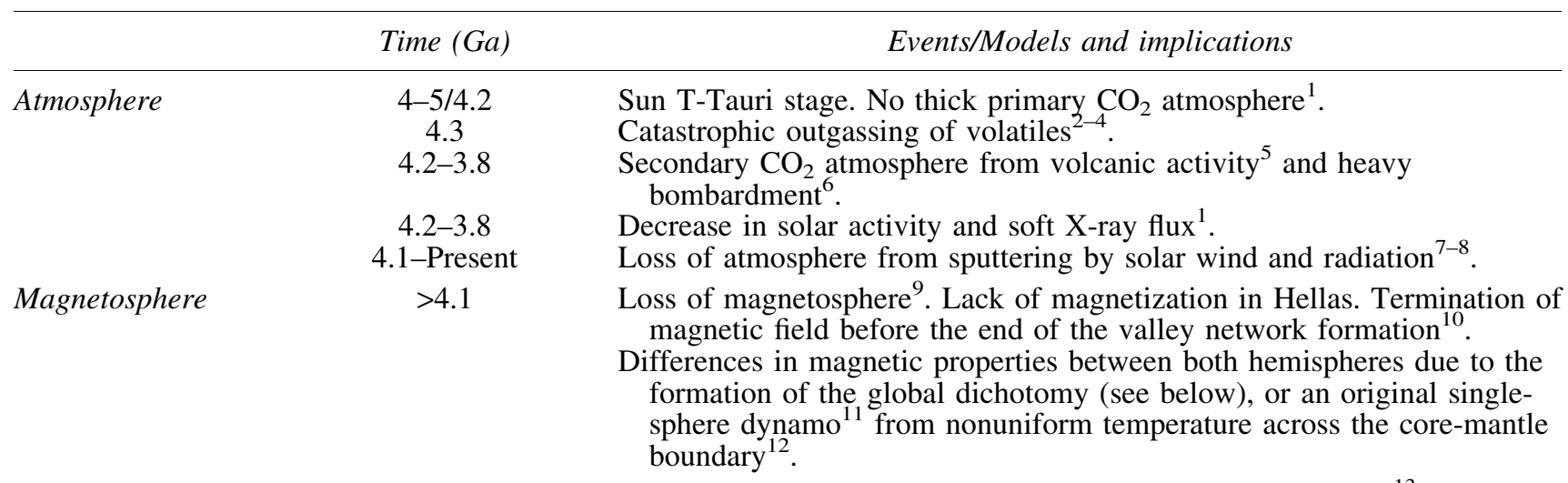

Global dichotomy

Its formation affects geography, climate, hydrology, geology ${ }^{13}$, and dispersal pathways for life. Externally driven models: A megaimpact or multiple impacts ${ }^{14-18}$ or a southern polar giant impact by a bolide 0.1-1.0 lunar mass ${ }^{19}$. The resulting magma ocean solidifies to form the thicker crust of the southern hemisphere ${ }^{20}$.

Internally driven models: Removal of the basal lowland crust by mantle convection $^{21-23}$ or plate tectonics ${ }^{24}$.

The global dichotomy forms during accretion or right after $^{25}$, making it the most ancient geological feature of Mars ${ }^{26-27}$.

Impact basins $\quad 4.1-3.9$

Structure Volcanism $\quad 3.8-3.5$

Hydrology
Most large impact basins form during the Noachian (Hellas, Argyre, Isidis, Utopia, other) ${ }^{27-29}$.

Valles Marineris develops and is subsequently modified by erosion and sedimentation into the Amazonian ${ }^{30-31}$. Volcanic activity into recent geological past ${ }^{32}$.

The rise of Tharsis generates rifting in Valles Marineris and Noctis Labyrinthus.

Elysium develops ${ }^{33-34}$, with activity into the Amazonian ${ }^{35}$.

Hydrological provinces and flow directions structurally defined early with the formation of the global dichotomy and the heavy bombardment ${ }^{36}$.

Peak of valley networks ${ }^{27,37-39}$ and lake formation ${ }^{40-42}$. Localized activity in the Amazonian. Networks are not fully integrated with the landscape, suggesting only short favorable conditions for their development ${ }^{39-47}$.

Outflow channels. Peak formation in the Hesperian with residual activity in the Amazonian ${ }^{27}$.

Ocean in the first billion years of history from subpermafrost aquifer modeling ${ }^{48}$ and from proposed geomorphic evidence ${ }^{49-51}$. Disputed model $^{52}$.

Oceanus Borealis (Hesperian ocean $)^{53-56}$. Cons: Difficulty to reconcile the volumes required to form the outflow channels with known volatile sources and sinks ${ }^{27}$, lack of fine-grained sediments ${ }^{57}$, evaporites ${ }^{58}$, carbonates $^{59-60}$, no evidence for Noachian glaciation ${ }^{61}$, and already thin Noachian atmosphere ${ }^{62-63}$. Pros: Lack of carbonates explained by destruction by precipitated $\mathrm{H}_{2} \mathrm{SO}_{4}{ }^{64}$ a globally acidic atmosphere ${ }^{65}$, or the short lifetime of ocean episodes ${ }^{54}$.

Other potential evidence: The global distribution of Hesperian deltas ${ }^{66}$, possibly tsunami deposits ${ }^{67-69}$, and shorelines ${ }^{49-51,70-73}$. The existence of shorelines has been debated since originally proposed ${ }^{53,74}$. The water global equivalent layer (GEL) has been used as a pro or con argument depending on models: $\mathrm{D} / \mathrm{H}$ enrichment factors argue for a large PreNoachian water loss $(\mathrm{GEL} \geq 137 \mathrm{~m})^{75}$. Ion-microprobe analysis implies a Pre-Noachian water loss greater than during the rest of the martian history (GEL $>41-99 \mathrm{~m}$ vs. GEL $>10-53 \mathrm{~m})$ and an undetected subsurface water/ice reservoir $(\sim 100-1000 \mathrm{~m}$ GEL) that exceeds the current observable inventory of $\sim 20-30 \mathrm{~m} \mathrm{GEL})^{76-77}$. A recent global reevaluation of eroded volumes of valley networks results in an even larger GEL of $\sim 5 \mathrm{~km}^{78}$. Other potential evidence includes polygonal ground in the lowlands ${ }^{7 \dot{9}}$ and subdued impact craters, whose anomalous depth/diameter ratio could be associated with a Late Hesperian ocean episode. ${ }^{53,80-83}$ 
TABle 1. (CONTINUED)

\begin{tabular}{|c|c|c|}
\hline & Time (Ga) & Events/Models and implications \\
\hline $\begin{array}{l}\text { Climate and } \\
\text { environmental } \\
\text { change }\end{array}$ & $4.1>$ & $\begin{array}{l}\text { Episodic periods of warmer and thicker atmosphere after the loss of the } \\
\text { magnetosphere contributed by orbital forcing }{ }^{84-85} \text { and volcanism. } \\
\text { Sulfur }{ }^{86} \text { and sulfates }{ }^{58,87-88} \text { suggest the release of greenhouse gases }{ }^{89-92} \text {. } \\
\text { Other warming mechanisms ( } \leq 10 \text { million years) include carbonate- } \\
\text { silicate cycles } \text {. Impact cratering provided transient environmental/ }^{93} \text { Itmospheric changes } 94 \text {. } \\
\text { Excursions of warmer periods on a cold early Mars are supported by the } \\
\text { presence of phyllosilicates } 95-99 \text { and increasingly more arid conditions } \\
\text { from the Hesperian on, with an abundance of sulfates and evaporites }{ }^{58} \text {. } \\
\text { Significant variations in obliquity, eccentricity, and precession }{ }^{84} \text { have also } \\
\text { led to a redistribution of water in the polar ice deposits to lower latitudes } \\
\text { to create ice ages regularly during martian history }{ }^{100} \text {. }\end{array}$ \\
\hline
\end{tabular}

References in the table: ${ }^{1}$ Erkaev et al., 2014; ${ }^{2}$ Elkins-Tanton, 2008, 2011; ${ }^{3}$ Tian et al., 2009; ${ }^{4}$ Brasser, 2013; ${ }^{5}$ Grott et al., 2011; ${ }^{6}$ Alexander et al., 2012; ${ }^{7}$ Jakosky and Phillips, 2001; ${ }^{8}$ Jakosky et al., 2017; ${ }^{9}$ Acuña et al., 1999; ${ }^{10}$ Fassett and Head, 2011; ${ }^{11}$ Stanley et al., 2008; ${ }^{12}$ Zhong and Zuber, 2001; ${ }^{13}$ Watters et al., 2007; ${ }^{14}$ Frey and Schultz, 1988; ${ }^{15}$ Wilhelms and Squyres, 1984; ${ }^{16}$ Andrews-Hanna et al., 2008; ${ }^{17}$ Marinova et al., 2008; ${ }^{18}$ Nimmo et al., 2008; ${ }^{19}$ Leone et al., 2014; ${ }^{20}$ Reese et al., $2011 ;{ }^{21}$ Lingenfelter and Schubert, $1973 ;{ }^{22}$ Wise et al., 1979; ${ }^{23} \mathrm{McGill}$ and Dimitriou, 1990; ${ }^{24}$ Sleep, 1994; ${ }^{25}$ Frey, 2003; ${ }^{26}$ Solomon et al., $2005 ;{ }^{27}$ Carr and Head, 2010; ${ }^{28}$ Frey, 2008 ; ${ }^{29}$ Andrews-Hanna and Zuber, 2010; ${ }^{30}$ Lucchitta, 2010; ${ }^{31}$ Watkins et al., 2015; ${ }^{32}$ Broz et al., 2017; ${ }^{33}$ Werner, 2009; ${ }^{34}$ Robbins et al., 2011; ${ }^{35}$ Greeley and Spudis, 1981; ${ }^{36}$ de Hon, 2010; ${ }^{37}$ Carr, $1996 ;{ }^{38}$ Gulick and Baker, 1989; ${ }^{39}$ Craddock and Howard, 2002; ${ }^{40} \mathrm{Cabrol}$ and Grin, 1999; ${ }^{41}$ Cabrol and Grin, 2010; ${ }^{42}$ Fassett and Head, 2008; ${ }^{43}$ Hynek and Phillips, 2003; ${ }^{44}$ Stepinski and Collier, 2004; ${ }^{45}$ Howard et al., 2005; ${ }^{46}$ Carr, 2012; ${ }^{47}$ Craddock and Lorenz, 2017; ${ }^{48}$ Clifford and Parker, 2001; ${ }^{49}$ Parker et al., 1989; ${ }^{50}$ Parker et al., 1993; ${ }^{51} \mathrm{Head}$ et al., 1998 ; ${ }^{52}$ Carr and Head, 2003; ${ }^{53}$ Baker, 2001; ${ }^{54}$ Dohm et al., 2001; ${ }^{55}$ Dohm et al., 2009b; ${ }^{56}$ Świader, 2014; ${ }^{57}$ McEwen et al., 2007; ${ }^{58}$ Bibring et al., 2006; ${ }^{59}$ Ehlmann et al., 2008; ${ }^{60}$ Wray et al., 2009; ${ }^{61}$ Wordsworth, 2016; ${ }^{62} \mathrm{Hu}$ et al., 2015; ${ }^{63}$ Kite et al., 2014; ${ }^{64}$ Levine and Summers, 2008; ${ }^{65}$ Greenwood and Blake, 2006; ${ }^{66} \mathrm{Di}$ Achille and Hynek, 2010; ${ }^{67}$ Rodriguez et al., 2015; ${ }^{68}$ Rodriguez et al., 2016; ${ }^{69} \mathrm{Costard}$ et al., 2017; ${ }^{70}$ Thompson and Head, 2001; ${ }^{31}$ Perron et al., 2007; ${ }^{72} \mathrm{Head}, 2007 ;{ }^{73}$ Banfield et al., $2015 ;{ }^{74}$ Malin and Edgett, 1999; ${ }^{75} \mathrm{Villanueva}$ et al., 2015; ${ }^{76}$ Kurokawa et al., 2014; ${ }^{77}$ Stuurman et al., 2016; ${ }^{78}$ Luo et al., 2017; ${ }^{79}$ Kargel et al., 1995; ${ }^{80}$ Boyce et al., $2005 ;{ }^{81}$ Mouginot et al., 2012; ${ }^{82}$ Gulick et al., 1997; ${ }^{83}$ Kreslavsky and Head, 2002; ${ }^{84}$ Laskar et al., 2002; ${ }^{85}$ Mischna et al., $2003 ;{ }^{86}$ Clark et al., 1976 ; ${ }^{87}$ Gendrin et al., 2005; ${ }^{88}$ Ehlmann and Edwards, 2014; ${ }^{89}$ Postawko and Kuhn 1986; ${ }^{90}$ Yung et al., 1997; ${ }^{91} \mathrm{Halevy}$ and Head, 2014; ${ }^{92}$ Ramirez et al., 2013; ${ }^{93}$ Batalha et al., 2016; ${ }^{94}$ Segura et al., 2002; ${ }^{95}$ Carter et al., 2013; ${ }^{96}$ Poulet et al., 2008; ${ }^{97}$ Bishop et al., 2005 ;

${ }^{98}$ Fairén et al., 2010; ${ }^{99} \mathrm{Head}$ et al., 2003; ${ }^{100} \mathrm{Head}$ et al., 2010.

vents and enable early life to use free electrons to synthesize compounds necessary for its evolution (e.g., Roussel et al., 2008; Ishii et al., 2015). Pre-Noachian paleomagnetic stripes are consistent with proto plate tectonics processes in the cratered highlands (e.g., Connerney et al., 1999), and large-scale strike-slip faulting is being interpreted as evidence of a slow, still-evolving, two-plate planet system in Valles Marineris (e.g., Yin, 2012). If these interpretations stand, Pre-Noachian Mars had the elements of a "habitability trinity" (Dohm and Maruyama, 2015).

Pathways and exchanges between the ocean and the deep subseafloor have generated the largest reservoir of prokaryotic life on Earth (e.g., Whitman et al., 1998; Amend and Teske, 2005; Edwards et al., 2012; Jungbluth et al., 2016; Hoshino et al., 2017). The oceanic crustal aquifer represents about $2 \%$ of the ocean's volume (e.g., Edwards et al., 2011) and extends several hundreds of meters into deeply buried sediments (e.g., Parkes et al., 1994; Roussel et al., 2008). Thick sediment layers act as a barrier to seawater-basalt exchange in places, while in others, exposed rocky outcrops facilitate fluid exchanges between the deep ocean and the crustal aquifer (e.g., Meyer et al., 2016). The intensity of fluid circulation is a function of geological settings and is more pronounced in heat-driven fluid flow areas, such as deep sea vents (e.g., Fisher et al., 2007).

Dispersal pathways during, and post, primordial ocean times would have depended on global fluid circulation in rocks and groundwater migration, which both have climatic, physical, and chemical components. On Mars, strong cyclic climate swings (e.g., Laskar et al., 2002) would have impacted the long-term stability of unconfined and shallow confined aquifers and their physicochemical properties such as texture, pore size, nutrients, chemistry, which are critical to their ability to support microbial ecosystems and biodiversity (e.g., Ghiorse and Wilson, 1988).

The early formation of the global dichotomy (Table 1), and the theoretical presence of islands and landmasses in a primordial ocean scenario, gives life access to land as early as the Pre-Noachian through subaerial pathways (e.g., shallow ocean margin, coastal regions, streams) and subsurface and underground fluid circulation in a fractured regolith and crust (e.g., Edwards et al., 2012; Fisher et al., 2015). Away from a protective deep water column, Pre-Noachian subaerial habitats, if any, would have been, from that time on, directly exposed to the heavy bombardment, climate variability, a magnetosphere that shut down $\sim 4.1 \mathrm{Ga}$, and a dissipating atmosphere.

The existence of a Pre-Noachian ocean has more theoretical than empirical support, and there is no strong geomorphic or mineralogical evidence at current resolution for its survival late into the Noachian. This period corresponds to the heavy bombardment and the formation of the giant impact basins (e.g., Hellas, Argyre, Isidis) by very large asteroids (e.g., Carr and Head, 2010), and the Barberton greenstone belt in South Africa (3.5-3.2 Ga) may offer an analogy to what could have been the fate of a primordial ocean on Mars, with impacts boiling and vaporizing the ocean's top layer (e.g., Sleep and Lowe, 2014).

The presence of a primordial ocean may not have been necessary for an origin of life on Mars. Alternatively (or concurrently) to an ocean, volcanic aquifers have been proposed 
as robust settings for an origin of life on Earth, with a wide range of physicochemical conditions for the formation of prebiotic organic compounds and RNA (e.g., Washington, 2000). Contrary to a theoretical primordial ocean, there is ample evidence that volcanic aquifers formed on Mars (e.g., Boston et al., 1992; Farmer, 1996; Mouginis-Mark and Christensen, 2005; Cousins and Crawford, 2011; Rodríguez and van Bergen, 2015). Volcanism was globally active since crustal formation $(4.3 \mathrm{Ga})$, with possible recent residual magmatic activity (e.g., Neukum et al., 2004; Broz et al., 2017). Massive volcanic constructs attest to repetitive eruptions over billions of years over hotspots (e.g., McEwen et al., 1999; Werner, 2009; Baratoux et al., 2013), these regions providing relative spatiotemporal durability to martian habitats (e.g., Schulze-Makuch et al., 2005; Westall et al., 2013).

Volcanic aquifers could have sustained long-term subsurface sheltered habitats against changing surface conditions after $4.1 \mathrm{Ga}$, with cycling of water, energy, and nutrients (e.g., Fairén et al., 2003; Schulze-Makuch et al., 2007), as well as transient subaerial habitats in hydrothermal springs, geysers, and pools (e.g., Walter and Des Marais, 1993; Cady and Farmer, 1996; Farmer, 1996; Walter, 1996; Gulick, 1998; Farmer and Des Marais, 1999; Cady et al., 2003; Allen and Oehler, 2008; Hofmann et al., 2008). Impact cratering produced an additional source of hydrothermal systems lasting up to tens of thousands of years for the largest impacts (e.g., Cabrol and Grin, 2001; Abramov and Kring, 2005; Newsom, 2010; Osinski and Pierazzo, 2012). On Earth, these environments are conducive to hypogene and supergene clay formation (e.g., Hazen et al., 2013). They are associated with weathering in acidic environments near active volcanoes, diagenesis, hydrothermal and other aqueous alterations (Table 1), and with the serpentinization of preexisting minerals (e.g., Schulte et al., 2006; Ehlmann et al., 2010; Chassefière et al., 2013; Greenberger et al., 2015). Serpentinization of basalt and other mafic igneous lithologies coupled with seawater-basalt interactions (if an ocean was present) would have provided an environment stimulating the confinement function for biomolecules and biochemical reactions in clay hydrogels (e.g., Yang et al., 2013).

Assuming these hypothetical environments as conducive to the emergence of life, Pre-Noachian biological dispersal pathways could have engaged

(a) deep crustal aquifers (hundreds to thousands of meters' depth) of volcanic and/or oceanic origin, maintained by the geothermal gradient at global scale and phreato-magmatic activity at regional scale. Unless disrupted by large impact events, these environments could have produced stable deep habitats over hundreds of millions to billions of years, with some possibly still sustained in recent geological times (e.g., Broz et al., 2017);

(b) an active subsurface ( $1 \mathrm{~m}$ to hundreds of meters' depth), with habitats connected by surface and subsurface fluid circulation, phreato-magmatic activity, and local surface/atmosphere interactions, such as topography and slope exposure, moisture penetration, and sediment texture and composition. Climate variability (e.g., obliquity cycles, freeze/thaw cycles and active layers) and stochastic events (e.g., impact cratering, volcanic eruptions) regularly affected habitat evolution (i.e., expansion, reduction, destruction) and connectivity networks; and

(c) an unstable surface environment with a high rate of habitat changes linked to climate variability, atmosphere/surface interactions, stochastic events (e.g., cosmic, environmental), and the state of the magnetosphere, atmosphere, and hydrosphere.

Recent missions have brought a greater focus on the various ways in which these environments would have been affected by early planetary changes (Sections 4-6). MAVEN's ${ }^{38} \mathrm{Ar} /{ }^{36} \mathrm{Ar}$ measurements show that Mars rapidly lost over $65 \%$ of its atmospheric argon through sputtering by pickup ions (e.g., Jakosky et al., 2017). The inferred loss of $\mathrm{CO}_{2}$ and $\mathrm{O}$ suggests an early partial pressure of 1 bar $\mathrm{CO}_{2}$ and a large early atmospheric loss from intense solar extreme UV radiation during the Sun T-Tauri stage (e.g., Rahmati et al., 2015; Airapetian et al., 2016). The strong decline in valley network formation by the end of the Noachian (e.g., Carr and Head, 2010) and changes in mineralogy (e.g., Bibring et al., 2006; Murchie et al., 2009) attest to this atmospheric transition.

\section{The Noachian Paradox}

Magnetosphere loss $\sim 4.1 \mathrm{Ga}$, atmospheric escape, frequent climate swings, and a distinct internal dynamic (Table 1) are the foundational parameters that would have differentiated a martian biosphere from Earth's very early and impacted the spatiotemporal evolution of its microbial biogeography in unique ways (e.g., Fierer, 2008). Species facing changing environments and habitat destabilization need functionally connected networks of habitats to adapt (e.g., Capone and Hutchins, 2003; Jansson and Taş, 2014; Zeglin, 2015), and the success of these networks relies on species that have sufficient dispersal ability to track suitable habitats. The mechanisms and extent of terrestrial microbial dispersal are still debated (e.g., Fierer, 2008; Nemergut et al., 2011, 2013); some propose that high abundance increases the probability of long travels by individuals and the colonization of remote locations by chance (e.g., Fontaneto and Hortal, 2012), while others argue that geographic barriers and physical isolation drive microbial evolution (e.g., Papke and Ward, 2004), with dispersal distances varying between microbial taxa (e.g., Martiny et al., 2006; Jenkins et al., 2007).

On Noachian Mars, passive and active biological dispersal agents were abundant, including gravity, water currents, impact ballistics, and atmosphere for the former and, potentially, microbial self-propulsion for the latter (e.g., Ebrahimi and Or, 2014; Petro et al., 2017). From an ecological standpoint, the heavy bombardment may have equally contributed to habitat formation and destruction, global dispersal, extinction, and biodiversification. It frequently reshaped the structure of the regolith and crust, facilitating fluid circulation in fractured and brecciated materials, thereby favoring microbial migration to new environments (e.g., Osinski and Pierazzo, 2012).

The Noachian is also the first geological period with a robust hydrologic record (e.g., Carr and Head, 2010). Currents and gravity influence aquifer and surface flow characteristics and play a central role in the distribution and 
types of habitats (e.g., Zeglin, 2015). Large impact basins formed in the Noachian. Many were associated with volcanic, lacustrine, and hydrothermal activity (Table 1) and presented habitable conditions (e.g., Cabrol and Grin, 2001, 2005; Varnes et al., 2003; Irwin et al., 2004; Fairén et al., 2005, 2016; Schulze-Makuch et al., 2005; Jepsen et al., 2007; Fassett and Head, 2008; Newsom, 2010; Cousins and Crawford, 2011; Schwenzer et al., 2012; Osinski et al., 2013; Retallack, 2014; Michalski et al., 2017). It can be expected, therefore, that during high obliquities - given that liquid water could circulate at the surface, through the regolith, and in the crust-microbial ecotones (i.e., transition zones that allow connectivity between microbial habitats [e.g., Borchers et al., 2015]) would have included fractured bedrock and clastic sediments (including their composition, texture, mineralogy, and albedo), the water interface between the unsaturated and saturated zones, and the groundwater/surface water interface (e.g., Griebler and Lueders, 2009; see also Table 2). Lakes, ponds, deltas, and rivers tapped into these aquifers through springs, catastrophic discharges, erosion, and surface water/ groundwater interfaces. Residence time of days for the surface, to centuries and millennia for kilometer-deep aquifers, is consistent with at least some subsurface and deep biotic material reaching the surface through these pathways and being subsequently dispersed. On Earth, this process supports pioneer microbial colonies, whose success and stability over time depend on interactions and interrelationships between populations and their adaptation to the environment (e.g., Kelly et al., 2014).

The early loss of the magnetosphere implies, however, that short UV radiation, that is, UVA, UVB, UVC, and ionizing radiation, increasingly reached the surface as the Noachian progressed (e.g., Hassler et al., 2014; Ehresmann et al., 2016). With a thinning atmosphere, radiation doses substantially increased (e.g., Atri et al., 2013), and radiation from muons would have impacted the subsurface with energetic secondary particle fluxes. When this process started, the probability of maintaining a long-term surface biosphere on Mars became very low regardless of the abundance and effectiveness of dispersal agents (e.g., Cockell et al., 2000; Rontó et al., 2003; Dartnell, 2011; Quinn et al., 2013; Wadsworth and Cockell, 2017).

Microorganisms and habitats are impacted differently by surface exposure (e.g., during catastrophic dispersal) or by accumulation doses (e.g., for a habitat and its biosignature preservation potential). Ultraviolet radiation on the surface has a $\sim 1000$-fold greater biocidal effect on Mars than on Earth (e.g., Beaty et al., 2006) and is rapidly lethal to exposed microorganisms (seconds to tens of minutes depending on microorganisms), although temporary survival is possible under a thin layer $(\leq 1 \mathrm{~mm})$ of dust or regolith (e.g., Rummel et al., 2014). By contrast, the Radiation Assessment Detector (RAD) on board the Curiosity rover measured a relatively constant and negligible ionizing radiation flux, mostly from galactic cosmic rays, and only one solar particle event over a period of 300 sols (e.g., Hassler et al., 2014). In the galactic cosmic ray case, biomolecules are compromised by dose accumulation, not instant exposure (300 million years down to $10 \mathrm{~cm}$ depth) (e.g., Pavlov et al., 2012), and sterilization depth and destruction may vary depending on the mineralogical composition and structure of the subsurface (e.g., Gómez et al., 2010; Ertem et al., 2017).
The Noachian presents, therefore, a paradox whereby primitive life could have occupied diverse and widespread environments and migrated through numerous dispersal mechanisms, but where a surface and subsurface sterilization process became active early and at global scale (e.g., Jakosky et al., 2017). Resolving this paradox is critical to understanding whether any types of durable Noachian subaerial habitats were possible, whether life had enough time to produce biomass in concentration that could be detected by mission payloads only reaching within a few centimeters to a meter at best into the regolith, and whether conditions were ever met to preserve such a record.

Resolving this paradox entails gauging the unique complexity of the martian environment, which goes well beyond understanding the individual impact of the loss of the magnetosphere or that of the declining atmosphere on biological processes. The unique complexity of Mars, even in these early stages, resided in the combination of a multitude of environmental extremes and the variability of their interplay over time. Some parameters declined in time (magnetosphere, atmosphere, energy); others still had distinct spatiotemporal effects depending on obliquity (e.g., water, ice distribution). For example, although the loss of the atmosphere was ultimately linked to that of the magnetic field, weak fields are less of a factor in surface radiation doses than the loss of atmospheric depth, the latter increasing doses by orders of magnitude (vs. folds for the former) (e.g., Atri et al., 2013). Changes in the atmospheric shield were therefore not only a factor of time but also a factor of obliquity (e.g., Jakosky and Phillips, 2001; Kreslavsky and Head, 2005), and this unpredictability in the radiation environment is only one of many factors (e.g., temperature, desiccation, geochemical, and textural changes in sediment) exposed microorganisms would have had to contend with.

To date, we only have a limited understanding of the effect of environmental polyextremes on microorganisms (e.g., Seckbach et al., 2013). This fundamental gap in knowledge has the potential to impair the exploration of planetary biosignatures whether on Mars or beyond, as individual coevolution on planets and moons will be shaped differently by distinct synergistic spatiotemporal changes between environmental parameters and life adaptation. The study of early martian lake analogues in the Andes (e.g., Cabrol et al., 2007b, 2009 , 2014) provides some insights into the impact of environmental polyextremes on shallow aquatic habitats relevant to Noachian Mars and reveals complex loops and feedback mechanisms. For instance, although high salinity preserves liquid habitat by depressing the freezing point of water, it allows UV to penetrate the water column and exposes life to radiation. As water evaporates, increased total dissolved solids in lakes amplify UV scattering, thereby attenuating the penetration and impact of radiation. In ice-covered lakes, short UV are screened, but less photosynthetically active radiation reaches the water column (e.g., Cabrol et al., 2009). In these polyextreme environments, the relative spatiotemporal influence of each parameter is a critical element in the evolution of microbial habitats (e.g., Cabrol et al., 2007c) and may vary on very short timescales (days, weeks, seasons). While rapid climate change at the global scale is the fundamental force driving the current retreat of glaciers and lakes in the Central Andes (e.g., Bradley et al., 2006; Rabatel et al., 2013), local factors such as reduced watersheds, energy sources, mineralogy, geochemistry, exposure, sediment texture, 
Table 2. Environmental Elements of Microbial Ecosystems on Mars Through Time

\begin{tabular}{|c|c|}
\hline $\begin{array}{l}\text { Habitable } \\
\text { environments }\end{array}$ & Habitats \\
\hline \multirow[t]{4}{*}{ Ocean $^{1}$} & Water surface \\
\hline & Water column \\
\hline & Deep sea vents \\
\hline & Subseafloor aquifer \\
\hline \multirow[t]{3}{*}{$\begin{array}{l}\text { Volcanic } \\
\quad \text { aquifer }^{1}\end{array}$} & $\begin{array}{l}\text { Pools, springs, spring } \\
\text { mounds, geysers, } \\
\text { mudpots }\end{array}$ \\
\hline & $\begin{array}{l}\text { Pore spaces (e.g., catenary, } \\
\text { cul-de-sac), grain texture, } \\
\text { and mineralogy }\end{array}$ \\
\hline & $\begin{array}{l}\text { Deep rock structure, texture, } \\
\text { temperature }\end{array}$ \\
\hline \multirow[t]{2}{*}{ Stream $^{1}$} & Water column \\
\hline & $\begin{array}{l}\text { Pore spaces (e.g., catenary, } \\
\text { cul-de-sac), grain texture, } \\
\text { and mineralogy } \\
\text { Interstitial pore water in } \\
\text { sediment and aquifer } \\
\text { Subglacial }\end{array}$ \\
\hline Lake ${ }^{1}$ & Water surface \\
\hline
\end{tabular}

Water column

Lake bed sediment

Hydrothermal input (impact crater lake, volcanic lake) Ice (ice-covered lake)

$I c e^{2-4}$

Crystals in glacier and snow

Spring mound, sediment texture

Debris-rich basal ice

Permafrost ${ }^{5-6}$

$\operatorname{Rock}^{7-8}$

Soil/Sediment ${ }^{9}$

Ice, regolith, sediment, pore spaces, water lenses

Cracks, pores, vesicles, weathered surfaces, mineral type and optical properties

Intergranular spaces, pores, grain texture

Salt/Evaporite ${ }^{10}$ Saline soils, hypolithic and endolithic habitats, hygroscopic minerals

Cavity/Cave $e^{1} \quad$ All habitats above
Microbial ecotones

Dispersal pathways

Shallow ocean margins/land transition

Transition zones of temperature, light, pressure, minerals, salts, chemistry, gases

Temperature, chemistry, gases, minerals

Crust/sediment exchange

Surface water/groundwater interface, chemistry, mineralogy, temperature, biofilms

Water interface: unsaturated/saturated zone

Rock/confining bed (clays)/clastic sediment interface

Surface water/groundwater interface, water chemistry, temperature, nutrient concentration; deltas, areas where water changes speed

Water interface: unsaturated/saturated zone

Surface water/groundwater interface, chemistry, mineralogy, temperature (See ice)

Shore/river/land transition, surface water/groundwater interface

Temperature, light, pressure, minerals, salts, chemistry, gases

Sediment texture, temperature, composition, geochemistry, water chemistry, gases

(See volcanic aquifer)

(See ice)

Pressure, temperature, gases, composition

Temperature, composition, rheology

Solid ice crystal/water-filled veins interface, ice/land transition

Temperature gradient, ice content, multiphase state of water, mineralogy

Mineral, albedo, composition change, face exposure, rock/soil and other transitions (e.g., endolithic, chasmolithic cryptoendolithic)

Soil/sediment transition, gas composition and content, land/water/ ice transitions, geochemical fluxes

Soil horizons, transitions in salt density, water content gradients, salt type, rock/sediment texture, composition, transparency

All ecotones above
Waves, wind, current, gravity, connectivity networks with estuaries, deltas, streams, and glaciers through subglacial flows

Currents, gravity, fluid fluxes

Currents, plumes and fluid fluxes, particulates

Fluid circulation, pore pressure and connectivity

Current, gravity, infiltration, pressure, plumes and fluid fluxes, wind

Recharge, underflow, discharge, current, gravity, pore geometry, fluid pressure

Pore geometry, pressure, connectivity, fluid pressure

Hydrologic connectivity and water intermittency in ephemeral and perennial streams, current, gravity

Pore pressure and connectivity, fluid circulation

Pore connectivity, fluid circulation

(See ice)

Wave, wind, current, gravity, connectivity networks with deltas, streams, and glaciers through subglacial flows

Currents, gravity, evaporation, wind

Currents, gravity, evaporation, desiccation, wind

(See volcanic aquifer)

(See ice)

Drainage from melt, infiltration, wind

Stream, current, gravity, infiltration, wind

Ice movement (in glaciers), meltwater, current, gravity, infiltration, wind

Melting, thawing, stream, gravity, active layers

Pore pressure, fluid circulation, wind, precipitation, thermokarst

Fluid circulation, wind, precipitation, saltation

Deliquescence solutions, fluid circulations, surface tension in rock matrix, capillary pressure, porosity, permeability, wind

All dispersal pathways above

\footnotetext{
${ }^{1}$ See text, references therein, and Table 1; ${ }^{2}$ Boetius et al., 2014; ${ }^{3}$ Montross et al., 2013; ${ }^{4}$ Lutz et al., 2017; ${ }^{5}$ Jansson and Taş, 2014; ${ }^{6}$ Steven et al., 2006; ${ }^{7}$ Walker and Pace, 2007; ${ }^{8}$ Blackhurst et al., 2005; ${ }^{9}$ Groffman and Bohlen, 1999; ${ }^{10}$ Davila and Schulze-Makuch, 2016.
} 

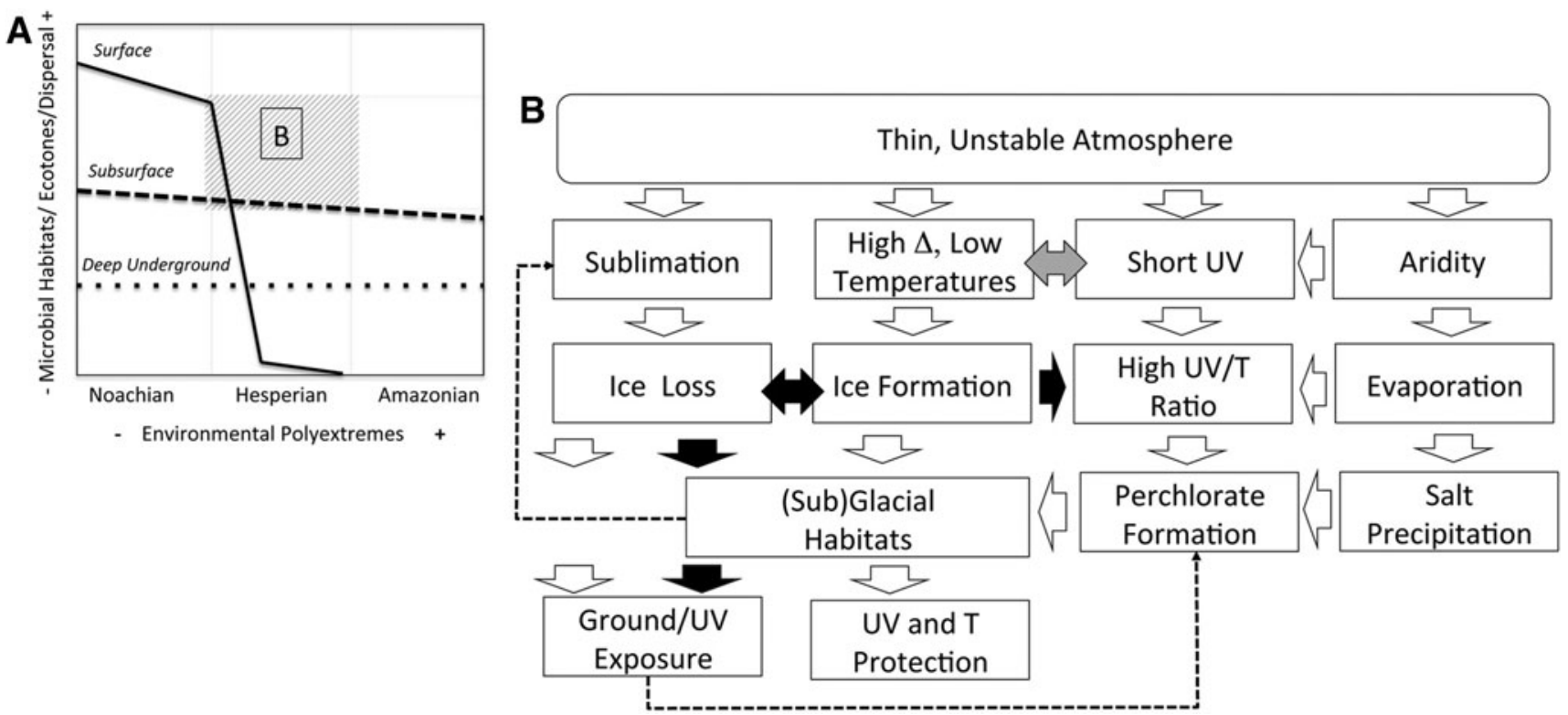

FIG. 2. Polyextreme environmental evolution of Mars. Mars became polyextreme very early. Its capability to preserve subaerial habitats, ecotones, and microbial dispersal pathways during the transitional period between the Noachian and Amazonian would have depended on fluctuating interactions between multiple environmental extremes and their relative dominance at any given time, which in part depended on time and obliquity. (A) Evolution of the abundance and diversity of microbial habitats, ecotones, and dispersal pathways over time as a function of increase in polyextremes (number and intensity). The impact is most severe for those at the surface (solid black line); it would have been less severe for those in association with the subsurface (dashed black line) and least severe for those of the deep underground (dotted line), where survivability would have depended primarily on the evolution of geothermal energy and deep water circulation. The straight lines show temporal trends, while evolution would have varied with obliquities. (B) Interactions between extreme environmental parameters. White arrows = promote; black arrows = prevent; left-right black arrows =counter; left-right gray arrow $=$ combine; dotted thin arrows show loop cycles.

water acquisition, and water temperature are what determine the rapidity at which habitats fluctuate and how they respond and evolve. This is reflected both in a hyper-adaptation and low biodiversity of the resident species (e.g., Cabrol et al., 2009; Demergasso et al., 2010), and by contrast, this creates a multitude of highly distinct colonies located only hundreds of meters from each other, thereby somehow augmenting regional biodiversity.

Mars became environmentally polyextreme early. How this might have translated into a biosphere, habitats, metabolisms, and dispersal pathways (Table 2) would depend on whether microorganisms ever resided at the surface, in the subsurface, underground, or occupied a subset-or all—possible niches. If life resided deep underground, surface and subsurface variability would have had only limited impact on habitats (Fig. 2A). Assuming that a martian biosphere temporarily involved subaerial habitats in the Noachian, the picture depicted by the Andean lakes suggests an evolution toward polyextremophiles (Fig. 2B), hyper-adaptable microbial communities, and oases driven by highly localized factors. The footprint of such communities would depend on where habitat conditions are met and, in terrestrial extreme environments, is often as small as a crack in a rock, a slope exposure, or a specific mineralogy (e.g., NavarroGonzález et al., 2003; Warren-Rhodes et al., 2006; Wierzchos et al., 2006; Cabrol et al., 2007a; Azúa-Bustos et al., 2011; Davila et al., 2013).

When atmospheric depth became insufficient on Marsincluding during favorable obliquities (e.g., Head et al., 2003; Kahre et al., 2013; Mischna et al., 2013)—-the potential for the expansion of a surface biosphere came to a halt. MAVEN and other missions show through changes in atmospheric characteristics, hydrology, and mineralogy that this scenario had already unfolded by the end of the Noachian (Table 1). MAVEN's conclusions suggest that the last part of the Noachian may never have been environmentally stable enough to sustain long-term subaerial habitats. If that is the case, depending on the timing of their formation, many environments currently perceived as favorable for biosignature exploration may only have been the temporary receptacles of ephemeral biological communities cyclically flushed out of sheltered underground habitats, rather than thriving subaerial oases. Ultimately, Mars' capability to retain subaerial habitats, ecotones, and dispersal pathways during the transitional period between the more favorable Noachian and the hostile Amazonian would have depended on how multiple extremes interacted with each other, which ones dominated in time and during any given obliquities, and whether these interactions where beneficial or detrimental to individual ecosystems.

\section{The Great Hesperian Dispersal}

The Late Noachian signaled an environmental turning point that constrained the subaerial expansion of a biosphere. Yet a coevolution on Mars presents us with possibly another paradox, whereby the Hesperian would have been a highly effective time for biological dispersal. While a primordial ocean remains notional, a Hesperian ocean, or limited shallow seas 
(3.7-3.4 Ga), although debated (e.g., Carr and Head, 2015; Wordsworth, 2016), has stronger empirical and theoretical support (Table 1 and references therein). Despite the sharp decline in hydrological processes, many outflow channels are Hesperian in age and formed in the equatorial region (e.g., McKenzie and Nimmo, 1999; Baker, 2001; Dohm et al., 2001; Montgomery and Gillespie, 2005; Harrison and Grimm, 2008; Carr and Head, 2010; Fassett and Head, 2011) through the catastrophic release of lakes (e.g., Lucchitta, 2010), ice streams (e.g., Lucchitta, 2001), hydrate deposits (e.g., Kargel et al., 2007), or aquifers (e.g., Carr, 1996; Baker, 2001). The formation of episodic oceans in the northern hemisphere has been attributed to the release of these reservoirs.

With the prospect of subaerial habitats becoming increasingly unlikely after the Noachian, the processes linked to the long-term underground water circulation from the highlands to the lowlands (e.g., Clifford, 1993) could have been one of Mars' dispersal "highways" and produced over time the largest concentration of biomass in equatorial reservoirs near the boundaries of the global dichotomy. As these reservoirs were catastrophically released, and the ocean formed in the northern lowlands, this process could have resulted in a sudden and large-scale biological dispersal. Whether oceanic habitats formed in the Hesperian would have depended on the ability of microorganisms to adapt to new environmental conditions (e.g., Fairén et al., 2003). Theoretically, habitable environments and habitats previously described for a notional primordial ocean (e.g., deep sea vents, deep subseafloor crustal aquifers, Tables 1 and 2) could still have formed in a Hesperian northern ocean. The buildup of Tharsis at the equator in the same time frame was accompanied by intense faulting and volcanic activity. Both Valles Marineris and Tharsis were areas of high concentration and dissipation of energy through volcanic and tectonic activity (e.g., McKenzie and Nimmo, 1999; Yin, 2012; Leone et al., 2014). The connection of any ocean margins either directly or indirectly (through fault systems) to the Tharsis/Valles Marineris and Elysium provinces would have had conditions favorable to the development of hydrothermal activity over hundreds of millions of years (e.g., Farmer, 1996; Schulze-Makuch et al., 2005; Al-Samir et al., 2016) that possibly continue today (e.g., Dohm et al., 2009a; Broz et al., 2017). The Hesperian deltas (e.g., Di Achille and Hynek, 2010) provided connectivity networks back to land through transitional environments (estuarine, shallow marine, subseafloor aquifers). The duration of oceanic habitats and the spatial extent of biological dispersal would have depended on volatile sources and cycling, ocean structure (e.g., currents, bathymetry), extent, composition, microbial adaptation, and the sustainability of energy sources and nutrients (e.g., through hydrothermal sources and vents and the weathering of land on the surface). The development of shallow water habitats ultimately would have depended on the state of the atmosphere and the potential for the water column (e.g., depth, water chemistry) and sediment characteristics to attenuate short UV (e.g., Leavitt et al., 1997; Rhode et al., 2001; Cabrol et al., 2009; Häder and Gao, 2015).

At the opposite environmental extreme, Mars may have always been too cold for any ocean to form (e.g., Wordsworth, 2016). Yet biomass concentration and biological dispersal in the regolith and crust would still have been possible in this scenario through hydrothermal convection (e.g., Travis et al., 2003) and would have depended on depth, structure, and the physical and textural characteristics of the rocks to enable unrestricted pore fluid circulation. There is ample empirical evidence of Hesperian catastrophic floods and surface flows in the subtropical and equatorial regions of Mars (e.g., Carr, 1996, Table 1). Further, missions have provided unambiguous confirmation that lakes formed and water ponded (e.g., Ruff et al., 2014; Grotzinger et al., 2015a, 2015b, and Table 1). With a cold scenario, the question is not so much Mars' continued capability to move biomass during the Hesperian as it is what may have changed, that is, (i) the depth at which dispersal took place, (ii) the environmental conditions for the development of new habitats, and (iii) the preservation of biosignatures.

\section{An Amazonian Biosphere}

Catastrophic biological dispersal would have repeated through episodic outflow activity during the Middle Amazonian $(1.23-0.3 \mathrm{Ga})$ in the Tharsis region (e.g., SchulzeMakuch et al., 2005; Rodriguez et al., 2015) and possibly much more recently in Western Elysium (e.g., Plescia, 2003; Russell and Head, 2007; Balme et al., 2011) in an environment that was already hyperarid and cold. In theory, this succession of episodes designates the northern lowlands as a region where biomass could have been abundant, concentrated, and protected in repositories covered under thick sedimentary deposits (e.g., Boyce et al., 2005; Mouginot et al., 2012); see also Section 7.1.

Mars has been geologically more quiescent in the past 3 billion years. However, recent volcanic activity (e.g., Werner, 2009; Hauber et al., 2011; Broz et al., 2017) and volcanic/ice interactions (e.g., Mouginis-Mark et al., 1984; Head and Wilson, 2002; Lanz and Saric, 2009; Levy et al., 2017) show that energy and water were still present tens to hundreds of millions of years ago at depth in the equatorial region. Additionally, the availability of water ice within the top meter in the high latitudes (e.g., Levrard et al., 2004; Bandfield, 2007) makes the north polar and subpolar regions areas of interest, especially when associated with evidence of geologically recent volcanic activity (e.g., Hovius et al., 2008). The idea that volcanic/ice interactions could still host a modern-day biosphere in a wide range of latitudes and settings (e.g., Boston et al., 2001; Boston, 2010; Cousins and Crawford, 2011) is not new. However, recent evidence of volcanic activity in the Late Amazonian greatly reinforces the possibility of a still-active martian biosphere. In these regions, and in regions of active layers, biomolecules may be exposed at the surface cyclically in the deposits from recent gullies (e.g., Wynn-Williams et al., 2001), recurring slope lineae (e.g., McEwen et al., 2011), and periglacial and glacial deposits from recent high-obliquity cycles (e.g., Head et al., 2003). These regions currently fall under the labels of Uncertain Regions and Naturally Occurring Special Regions for exploration (e.g., Rummel et al., 2014).

\section{Discussion}

Potentials and limitations of the analogy we draw between early Earth and Mars are redefined with each new Mars mission, but a simple side-by-side comparison between 
the two planets viewed from space sends an already powerful message: Over 4 billion years of coevolution have resulted in a deep imprint of the biological processes over the terrestrial landscape, of which biomediated minerals (e.g., Bradley, 2015) and sedimentary bioconstructs (e.g., Walter et al., 1992; Summons et al., 2011) are only a few examples. Many biosignatures are visible from space (e.g., McCabe et al., 2016), and Earth's atmosphere is the first evidence of how influential biology has been in shaping the terrestrial environment (e.g., Lyons et al., 2014).

By comparison, Mars does not show any visible signs that biology ever had a significant impact on surface processes. If it did, it is at a resolution yet to be reached, or in ways we do not understand yet, and this alone is a critical piece of information. Nevertheless, the potential for an origin of life did exist on Mars, and despite all differences, it is possible to theoretically assemble an early martian biosphere from existing data. Yet the data also clearly show that ultimately, while life could have survived the heavy bombardment, as it did on Earth, early subaerial habitats may never have had the opportunity to rebound from an irreversible environmental change, as was often the case for our biosphere. Sometime during the Noachian, the elements of a coevolution of life and environment that involved the surface simply went away on Mars. The next step is thus to understand where this observation takes the search for biosignatures.

\subsection{Large biomass repositories}

Regardless of where life could have developed (ocean, volcanic aquifer, other), greater habitat stability on Mars consistently resided below the surface over time (Table 2). While early surface environmental conditions were equally extreme on Earth and Mars, the coevolution of life and environment on our planet led to a biosphere capable of expanding and occupying every niche, whereas a coevolution on Mars would have forced life-as we know it - to continuously shrink its surface footprint and ultimately retreat underground. This would not have prevented Mars from developing a deep, diverse, and extended biosphere. Many terrestrial lithoautotrophic microbial communities do not depend on surface organisms for primary production (e.g., Stevens, 1997). They reside in all physical spaces that provide minimum requirements for life (e.g., Jepsen et al., 2007; Harrison et al., 2013; Schulze-Makuch et al., 2015), including at the limit of habitability (e.g., Yanagawa et al., 2017), where their abundance and diversity are constrained by the availability of water, energy/nutrients, and carbon (e.g., Reith, 2011; Rempfert et al., 2017). Microorganisms in dark, nutrient-poor habitats live in biofilms attached to mineral surfaces (e.g., Jones and Bennett, 2017) and have adapted to specific minerals for their biogeochemical processes. Survival, growth, and community structure are linked to mineral chemistry and reactions at the microbe/mineral interface (e.g., Jones et al., 2011), and they survive in a wide range of environments using thermodynamic disequilibria within their geological settings (e.g., Gaidos and Selsis, 2007).

A coevolution approach to Mars shows that, over eons and with expected regional and latitudinal variability, microorganisms would likely have concentrated in the underground, forming deep biomass vaults (Fig. 3). Among those, Arabia Terra stands out as a unique topographic and hy- drologic collection area over 4 billion years. It represents a topographic trap for the underground water circulation originating in the southern regions of Mars (e.g., Clifford and Parker, 2001) and in Valles Marineris to the west (e.g., Carr, 1996; Baker, 2001; Dohm et al., 2001; Carr and Head, 2010), where recent volcanism (e.g., Broz et al., 2017) suggests that fluid circulation at depth could still be supported by magmatic activity. Although the origin of methane emissions in Arabia Terra has not been determined yet (e.g., Mumma et al., 2009; Etiope et al., 2013; Michalski and Bleacher, 2013), this specific location is to be expected from a deep biosphere perspective, that is, considering the interactions between lithosphere, hydrosphere, and energy resources (e.g., Chapelle et al., 2002; Schulte et al., 2006; Pirajno, 2009; Amils et al., 2014; Rempfert et al., 2017).

By definition, many of these deep vaults are located hundreds of meters below the surface and are thus not directly accessible by current exploration means. They could be designated as prime astrobiology investigation sites for future exploration (e.g., Niles et al., 2017), including deep drilling (e.g., Stoker et al., 2008), as current robotic coring systems can only reach a few centimeters to a meter into the subsurface (e.g., McKay et al., 2013; Zacny et al., 2013).

\subsection{Ecosystem exploration with rovers and detection thresholds}

Environmental evolution suggests that a biosignature "lowhanging fruit" may be rare at the surface of Mars, but two types of records are still theoretically within reach of current exploration means. The first one relates to materials extracted from their original geological settings by impact cratering and hydrogeologic activity (e.g., streams, glacial and periglacial processes, landslides, tsunamis). This record is now haphazardly distributed and out of context, and after $\sim 4$ billion years of environmental exposure might be difficult to decipher with current instrument detection levels. The other potential biosignature record may still be in situ and possibly survived destruction, and ideally, this is the one to be targeted by landing site selection for upcoming missions.

Central to the landing site selection process are the concepts of habitability, biosignature formation, and biosignature preservation potential (e.g., Mustard et al., 2013). They are currently evaluated primarily through geological, geochemical, and compositional evidence, rather than through an ecological and microbiological lens. From a coevolutionary standpoint, however, and with a mission goal to identify samples most likely to have retained biosignatures, it is essential for this approach to be supported by an ecosystemic perspective that focuses on microbial systems and what constitutes evidence (or lack thereof) of interactions between past microbial habitats, their occupants, and the environment (e.g., Cockell, 2010). Over the past decades, an abundance of physical data has been accumulated in support of the formation of habitable environments at the surface of Mars between the Noachian and the Hesperian, but whether these environments were ever inhabited (e.g., Cockell et al., 2016) is really what ultimately matters for the upcoming missions.

The current challenge is not in a lack of understanding as to what these interactions could be or the scale of evidence to search for (e.g., Summons et al., 2011; Ehlmann et al., 2016); it is in the lack of orbital data with adapted spatial 


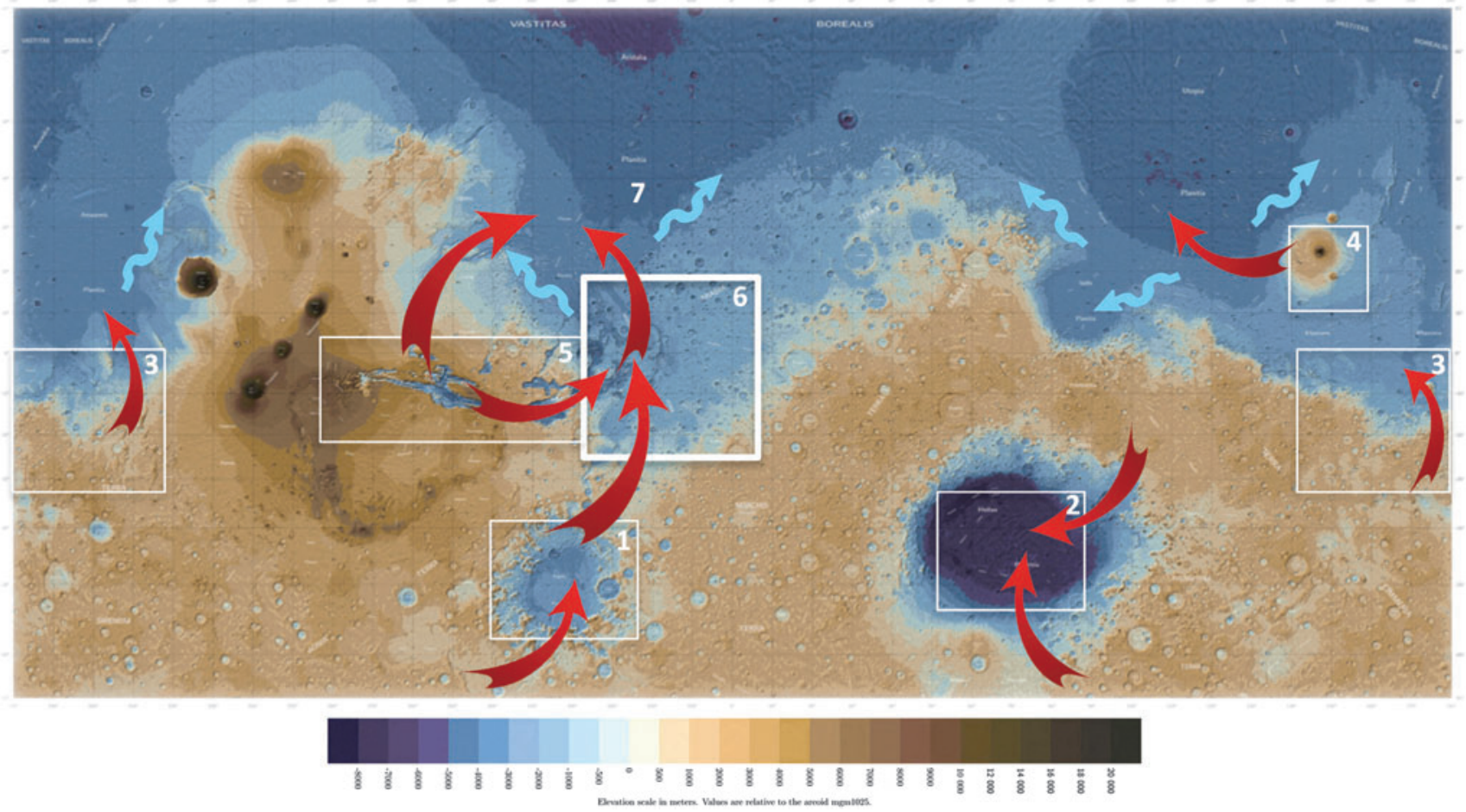

FIG. 3. Primary dispersal pathways and biomass repositories - the red arrows represent potential primary biological dispersal pathways; blue arrows are hypothetical shallow dispersal paths along costal marine currents; boxes indicate primary deep biomass repositories. The suggested surface areas are representative only. They include the following: (1) The south polar-Argyre-Chryse trough drainage system (Clifford and Parker, 2001), where Argyre collects polar basalt meltwaters. Surface discharges occurred through the Chryse trough (Parker et al., 1993; Fairén et al., 2016) into west Valles Marineris and an early northern ocean. Surface flow is questioned by Hiesinger and Head (2002), who favored subsurface drainage of a lake. Evidence supports an early habitable environment (e.g., Moore and Wilhelms, 2001; Hiesinger and Head, 2002; Fairén et al., 2016; Williams et al., 2017). (2) Hellas presents similar habitability potential as Argyre (e.g., Gulick, 1998; Schulze-Makuch et al., 2007, and references herein; Wilson et al., 2010). Hellas is a closed basin and the deepest point on Mars at $-7152 \mathrm{~m}$. Its seasonal atmospheric pressure $~ 89 \%$ higher than the surface (Grassi et al., 2007) allows transient surface liquid water episodes and glacial processes (e.g., Haberle et al., 2001) and the release of deep materials to the surface. (3) Sirrenum and Memnonia Fossae are structural troughs connected to Tharsis. They mark the origin of large lakes and channels, including in the Mangala and Ma'adim Vallis regions. The latter is additionally linked to volcanic/ hydrothermal systems from impact cratering (e.g., Gusev Crater) and volcanic activity (e.g., Apollinaris Patera). The exploration of Gusev confirmed a Noachian habitable environment, with geomorphic and mineralogical evidence presented as possible bioconstruct analogues (Ruff and Farmer, 2016). (4-5) Sustained volcanic and hydrothermal activity with cyclic accumulation of volatiles in equatorial aquifers makes the Tharsis/Valles Marineris and Elysium regions high-priority areas for deep biomass repositories. (6) Arabia Terra is an outstanding candidate repository. Topographically, it has been a surface, subsurface, and deep underground collection area over the entire history of Mars. Late Amazonian volcanism (Broz et al., 2017) shows modern magmatic processes and a potential for hydrothermal circulation that drains from Valles Marineris toward Arabia. The region is characterized by higher epithermal neutron count (e.g., Feldman et al., 2002) and methane plumes (e.g., Mumma et al., 2009; Oehler and Etiope, 2017). (7) The northern plains repository could theoretically be composed of biomass released from the highland through catastrophic releases of equatorial aquifers and from oceanic habitats. Other biomass repositories and deep dispersal pathways might include the equatorial belt at depth, where the highlands/lowlands flow circulation concentrated underground over billions of years; the planet's overall deep interior $(\geq 500 \mathrm{~m}$ ) - with water at depth, combined lithostatic pressure and geothermal gradient have maintained conditions to develop possible deep habitats over time since accretion. Microbial organisms migrating from subseafloor and/or volcanic aquifers could have colonized deep aquifers, caves (e.g., from chemical dissolution, ancient magma chambers, lava tubes, and underground rivers), cavities, mineral surfaces, and pore spaces (see Table 2). Mars analog studies have abundantly demonstrated the suitability of these environments for a broad range of microbial communities. Credit: The basemap was prepared by Daniel Macháček.

scale and spectral resolution to support a robust evaluation of the potential for such interactions in a landing ellipse prior to a mission. Broad-scale environmental habitability potential on Mars is identifiable from orbit with current exploration assets, and its pre-mission characterization has successfully supported previous landing site selections (e.g.,
Golombek et al., 2005). However, ancient potentially habitable environments might not translate into ancient habitats once at the surface. This data gap increases uncertainty in decision-making with respect to achieving the central mission goal and entirely shifts the burden to rover science operations for the upcoming missions. 
Current knowledge gaps will not be filled by the time Mars 2020 and ExoMars land, but biosignature exploration can be supported and uncertainties reduced in several ways. One is to identify missing detection thresholds from orbit to the ground. Through the NASA Astrobiology Institutefunded project Changing Planetary Environments and the Fingerprints of Life, ongoing research in extreme environments (e.g., Cabrol et al., 2015) is quantifying these thresholds for a variety of relevant microbial habitats by using satellite imagery and drones. Preliminary results (e.g., Phillips et al., 2017) show that, to be effective and diagnostic, the orbital resolution of a visible imager should reach $\sim 1 \mathrm{~cm} /$ pixel to resolve fine-scaled geomorphic features in microbialites, spring mounds, and salt habitats, which is beyond the recommendation of $\sim 10-15 \mathrm{~cm} /$ pixel for a future orbital visible imager (e.g., MEPAG NEX-SAG Report, 2015). HiRISE and a future orbiter with $\sim 10-15 \mathrm{~cm} /$ pixel resolution could identify bulk geomorphic features that are consistent with a potential habitat (e.g., Suosaari et al., 2016), but might still not be diagnostic for many of them (e.g., Allen and Oehler, 2008) unless data sets can be improved through new super-resolution techniques (e.g., Tao and Muller, 2016).

Combined with visible data, orbital spectral signatures are critical elements in ancient habitat detection. Interactions between microorganisms and their environment are captured through the presence of biomediated minerals (e.g., Röling et al., 2015). In that, CRISM resolution (e.g., Murchie et al., 2009) brings some support to habitat detection. While the instrument might not be able to resolve microbial habitats individually, the $\sim 6 \mathrm{~m}$ /pixel along-track oversampled hyperspectral imaging resolution (e.g., Kreisch et al., 2017) provides an important strategic tool for the identification of mineralogical transitions associated with potential habitats and ecotones. For example, $\sim 60 \mathrm{~m}$ spatial resolution is already capable of revealing temperature changes in hydrothermal springs reflected in changing mineralogies, and/or pigments of microbial colonies in these environments (e.g., Kruse et al., 2011).

Another means of supporting biosignature exploration prior to, and during, a mission is by integrating survey techniques developed in microbial ecology. Past and recent NASAfunded rover field experiments testing microbial habitat and biosignature exploration strategies at the surface and in the subsurface of the Atacama Desert (e.g., Wettergreen et al., 2005, Cabrol et al., 2007a) led to the development of ecological mapping techniques adapted to autonomous rover operations, and to the generation of predictive maps of habitat potential (e.g., Hock et al., 2007; Warren-Rhodes et al., 2007a, 2007b, and unpublished data; Smith et al., 2007). This is typically an area where advances in detection algorithms and machine learning can bring new support to biosignature detection, including from orbit through, for example, the segmentation of hyperspectral imagery, correlation of orbital and surface spectra, novelty detection, multiscale adaptive sampling, data segmentation and superpixel clustering, and biohint probability mapping, among others (e.g., Thompson et al., 2011; Candela et al., 2017).

In addition to a geological and environmental perspective, developing an ecosystemic view of a region prior to landing is absolutely essential to guide biosignature exploration. Research in terrestrial extreme environments and the exploration of the rare Archean record shows how challenging such an exploration can be with boots on the ground, and on Mars it will be performed within the operational constraints and scientific payload limitations of robotic systems. The support of robust orbital remote-sensing capabilities with relevant spatial and spectral resolution is thus foundational to the development of robotic exploration protocols for the search for biosignatures on Mars, but even more broadly to the development of autonomous biosignature exploration anywhere in the Solar System and beyond. It is fundamental not only to the preparation of a mission and the characterization of a landing ellipse but also to the planning of the future search for life beyond Earth. Tactically, drones supporting local rover exploration along a traverse could substantially increase our ability to develop dynamic spatiotemporal models of ancient ecosystem evolution along a traverse as we go during a mission (e.g., Pergola and Cipolla, 2016; Phillips et al., 2017). Strategically, however, having an understanding of habitat potential at global scale through orbital capabilities (vs. global habitability potential as we currently do) would help us design missions that are best adapted to the evidence we find (or the lack thereof), and optimize a long-term biosignature exploration strategy.

\section{Conclusion}

Whether a coevolution of life and environment ever took place on early Mars is unknown. However, the factors at play demonstrate the uniqueness of each planetary experiment, regardless of similarities with Earth. They also emphasize the differences between searching for biosignatures and characterizing habitability. Searching for biosignatures involves a systemic understanding of a coevolution, that is, the integration of what we have learned in past decades about Mars' habitability and environmental changes over time, with inferences we make about their impact on hypothetical biological processes and their constraints on habitats. Critically, it requires that we start thinking of Mars in terms of a biosphere, ecosystem, and ecology. It also leads us to explore the closest planetary paleoenvironment to early Earth, which is probably one of its greatest challenges.

In many ways, the obstacles of reconstructing a Noachian coevolution are comparable to those faced when trying to reconstruct the Archean coevolution, and the paucity of the early terrestrial record and its alteration illustrate the complexity of this task. For Mars, we still have to fully understand how regional and local hydrogeochemistry could have affected biogeochemical cycles and life size, composition, metabolism, morphology, and biosignatures (e.g., Summons et al., 2011). In that, the range of martian environments discovered shows both neutral and acidic conditions, which points to an early diversity comparable to Archean Earth. As Mars developed a more acidic hydrosphere in time, and the surface became more hostile, the likelihood for the production of substantial amounts of organic matter and large-scale biostructures in a subaerial context substantially decreased. In addition to a potentially low initial production of organic matter, deposits were subsequently affected by diagenesis, climate, tectonic and impact processes, and other physicochemical processes. This would have contributed to significant alteration of a biorecord and our ability to recognize it, although studies such as Río Tinto show that sedimentary deposits formed in a highly acidic and oxidizing environment 
record aspects of the physical, chemical, and biological environment of the regional ecosystem. This could indicate that preservation of some indicators through diagenesis and environmental influences might still have been possible on Mars (Amils et al., 2014).

Regardless of initial conditions, subaerial environments may never have been stable enough over extended periods of time, simply due to the high variability of the martian climate, this instability only growing over time with the loss of the atmosphere. Ultimately, the subsurface and the deep underground were always more stable and would have allowed the development of specialized microbial communities that had more time to thrive and accumulate large biomass deposits. Sheltered conditions would also have provided more favorable conditions for preservation.

Understanding how to search for biosignatures on Mars also entails filling in knowledge gaps with continuous research here on Earth. This includes, and possibly chiefly, the identification of detection thresholds; the design, testing, and implementation of autonomous biosignature and habitat detection methods; and the development of a better understanding of the evolution of polyextremophiles in complex environments and their physical, mineralogical, and biological signatures. As we think of Mars as a coevolution, we must also be prepared to envision all possible end-member terms, including the recognition that a martian biosphere may never have involved a surface expression, and anticipate the next steps along that path as well.

Further, we should consider a variety of complementary approaches to the exploration strategies currently deployed. In particular, although our understanding of early Mars in its first billion years remains fragmented, present-day Mars is a reflection of its past 3 billion years of history. We have now developed an understanding of the impact of orbital forcing and past and modern climate cycles at global to regional scales. However, a characterization of the high-resolution spatiotemporal scale of variability of the environment today has yet to be undertaken. Doing so would provide an immediate and uncertainty-free insight into the ecological potential of Mars' surface and near surface over the past 75\% of its environmental history. While life is not expected to survive near the surface today, understanding present surface conditions, the influence of the landscape (e.g., topography, geology, texture, albedo), and its variability at sufficient resolution to characterize the scale of microbial habitat, will identify the surface expressions of seasonal and perennial environmental "hotspots," which may be potential windows into subsurface and deeper biomass vaults. Such areas in terrestrial extreme environments are often characterized by unique conditions at multiple scales but particularly at the meter to micrometer scale (e.g., slope exposure, cracks in rocks, cavities in the mud of an ancient lake bed, surface/ atmosphere interactions). At these sites, parameters such as temperature, moisture, light, mineralogy, sediment texture, $\mathrm{pH}$, and others generally differ from the average ambient environment and remain stable over time for life to persist. In addition to high spatial and spectral resolution orbiters, high-resolution environmental arrays strategically deployed on Mars would dynamically map the distribution and concentration of these hotspots. Ultimately, this approach could become a cornerstone strategy for the exploration of Mars, as it supports three critical exploration goals: the search for biosignatures; human exploration (climate, weather, and activity planning); and planetary protection through the identification and characterization of environmental hotspots below current resolution and their spatial relationships with respect to present and future missions.

\section{Acknowledgments}

I would like to express my most sincere appreciation to those who, through constructive criticism, comments, and informal reviews have helped me articulate this perspective before submission. I am particularly in debt to Kim WarrenRhodes and Bill Diamond for their untiring support and invaluable input on the various iterations of the manuscript. Special thanks also go to David Darling, David Wettergreen, and Edmond Grin. I would also like to thank Chris McKay and a second, anonymous reviewer whose questions, comments, and suggestions helped improve this manuscript. This work finds its roots in the years of research in extreme environments supported by the NASA Astrobiology Institute with the High Lakes (2003-2008) and Changing Planetary Environment and the Fingerprints of Life (2015-2019) projects; in the development and field testing of rover field experiments with NASA's Astrobiology Science and Technology for Exploring Planets (ASTEP)-funded Life in the Atacama (2003-2006) and Subsurface Life in the Atacama (2011-2014) projects; and in my participation in the Mars Exploration Rover mission. This perspective also stems from the preparation of the 2016 AGU Sagan Lecture that I was honored to deliver in San Francisco and for which I extend my deepest gratitude to the AGU Biogeosciences Section.

\section{Author Disclosure Statement}

The author declares no conflict of interest.

\section{References}

Abramov, O. and Kring, D.A. (2005) Impact-induced hydrothermal activity on early Mars. J Geophys Res 110, doi: 10.1029/2005JE002453.

Acuña, M.H., Connerney, J.E.P., Ness, N.F., Lin, R.P., Mitchell, D., Carlson, C.W., McFadden, J., Anderson, K.A., Reme, H., Mazelle, C., Vignes, D., Wasilewski, P., and Cloutier, P. (1999) Global distribution of crustal magnetization discovered by the Mars Global Surveyor MAG/ER experiment. Science 284:790-793.

Airapetian, V.S., Glocer, A., Gronoff, G., Hébrard, E., and Danchi, W. (2016) Prebiotic chemistry and atmospheric warming of early Earth by an active young Sun. Nat Geosci 9:452-455.

Albee, A.L., Arvidson, R.E., Palluconi, F., and Thorpe, T. (2001) Overview of the Mars Global Surveyor mission. $J$ Geophys Res: Planets 106, doi:10.1029/2000JE001306.

Alexander, C.M.O'D., Bowden, R., Fogel, M.L., Howard, K.T., Herd, C.D.K., and Nittler, L.R. (2012) The provenances of asteroids, and their contributions to the volatile inventories of the terrestrial planets. Science 337:721-723.

Allen, C.C. and Oehler, D.Z. (2008) A case for ancient springs in Arabia Terra, Mars. Astrobiology 8:1093-1112.

Al-Samir, M., Nabhan, S., Fritz, J., Winkler, A., Bishop, J.L., Gross, C., and Jaumann, R. (2017) The Paleolacustrine evolution of Juventae Chasma and Maja Valles and its implications for the formation of interior layered deposits on Mars. Icarus 292:125-143. 
Amend, J.P. and Teske, A. (2005) Expanding frontiers in deep subsurface microbiology. Palaeogeogr Palaeoclimatol Palaeoecol 219:131-155.

Amils, R., González-Toril, E., Fernández-Remolar, D., Gómez, F., Aguilera, Á., Rodríguez, N., Malki, M., García-Moyano, A., Fairén, A.G., de la Fuente, V., and Luis Sanz, J. (2007) Extreme environments as Mars terrestrial analogs: the Río Tinto case. Planet Space Sci 55:370-381.

Amils, R., Fernández-Remolar, D., and the IPBSL Team. (2014) Río Tinto: a geochemical and mineralogical terrestrial analog of Mars. Life 4:511-534.

Anand, M., Russell, S.S., Blackhurst, R.L., and Grady, M.M. (2006) Searching for signatures of life on Mars: an Fe-isotope perspective. Philos Trans R Soc Lond B Biol Sci 361:17151720.

Andrews-Hanna, J.C. and Zuber, M.T. (2010) Elliptical Craters and Basins on the Terrestrial Planets, Geological Society of America Special Paper 465, Geological Society of America, Boulder, CO.

Andrews-Hanna, J.C., Zuber, M.T., and Banerdt, W.B. (2008) The Borealis Basin and the origin of the martian crustal dichotomy. Nature 453:1212-1215.

Armstrong, H.A and Brasier, M.D. (2004) The origin of life and the early biosphere. In Microfossils, $2^{\text {nd }}$ ed., Blackwell Publishing, Malden, MA, pp 37-47.

Atri, D., Hariharan, B., and Grießmeier, J.M. (2013) Galactic cosmic ray-induced radiation dose on terrestrial exoplanets. Astrobiology 13:910-919.

Azúa-Bustos, A., González-Silva, C., Mancilla, R.A., Salas, L., Gómez-Silva, B., McKay, C.P., and Vicuña, R. (2011) Hypolithic cyanobacteria supported mainly by fog in the coastal range of the Atacama Desert. Microb Ecol 61:568-581.

Azuma, S., Yamamoto, S., Ichikawa, H., and Maruyama, S. (2017) Why primordial continents were recycled to the deep: role of subduction erosion. Geoscience Frontiers 8:337-346.

Baker, V.R. (2001) Water and the martian landscape. Nature 412:228-236.

Balme, M.R., Gallagher, C.J., Gupta, S., and Murray, J.B. (2011) Fill and spill in Lethe Vallis: a recent flood-routing system in Elysium Planitia, Mars. Geol Soc Spec Publ 356: 203-227.

Bandfield, J.L. (2007) High-resolution subsurface water-ice distributions on Mars. Nature 447:64-67.

Banfield, D., Donelan, M., and Cavaleri, L. (2015) Winds, waves and shorelines from ancient martian seas. Icarus 250: 368-383.

Baratoux, D., Toplis, M.J., Monnereau, M., and Sautter, V. (2013) The petrological expression of early Mars volcanism. J Geophys Res: Planets 118: 59-64.

Baross, J.A. and Hoffman, S.E. (1985) Submarine hydrothermal vents and associated gradient environments as sites for the origin and evolution of life. Orig Life Evol Biosph 15:327345 .

Batalha, N.E., Kopparapu, R.K., Haqq-Misra, J., and Kasting, J.F. (2016) Climate cycling on early Mars caused by the carbonate-silicate cycle. Earth Planet Sci Lett 455:7-13.

Beaty, D.W., Buxbaum, K.L., Meyer, M.A., Barlow, N.G., Boynton, W.V., Clark, B.C., Deming, J.W., Doran, P.T., Edgett, K.S., Hancock, S.L., Head, J.W., Hecht, M.H., Hipkin, V., Kieft, T.L., Mancinelli, R.L., McDonald, E.V., McKay, C.P., Mellon, M.T., Newsom, H., Ori, G.G., Paige, D.A., Schuerger, A.C., Sogin, M.L., Spry, J.A., Steele, A., Tanaka, K.L., and Voytek, M.A. (2006) Findings of the Mars Special Regions Science Analysis Group, unpublished white paper posted June 2006 by the Mars Exploration Program Analysis Group (MEPAG) at https://mepag.jpl.nasa.gov/ reports.cfm

Beegle, L.W., Bhartia, R., DeFlores, L., Abbey, W., Carrier, B., Asher, S., Burton, A., Conrad, P., Clegg, S., Edgett, K.S., Ehlmann, B., Fries, M., Hug, W., Reid, R., Kah, L., Nealson, K., Minitti, M., Popp, J., Langenhorst, F., Orphan, V., Sorbon, P., Steele, A., Tarcea, N., Wanger, G., Wiens, R., Williford, K., and Yingst, R.A. (2016) SHERLOC: an investigation for Mars 2020 [abstract 2022]. In Biosignature Preservation and Detection in Mars Analog Environments I: Paleo-Hydrothermal Systems, Lunar and Planetary Institute, Houston.

Bell, E.A, Boehnke, P., Harrison, T.M., and Mao, W.L. (2015) Potentially biogenic carbon preserved in a 4.1 billion-yearold zircon. Proc Natl Acad Sci USA 112:14518-14521.

Beraldi-Campesi, H. (2013) Early life on land and the first terrestrial ecosystems. Ecol Process 2, doi:10.1186/21921709-2-1.

Bercovici, D. and Ricard, Y. (2014) Plate tectonics, damage and inheritance. Nature 508:513-516.

Bibring, J.-P., Langevin, Y., Gendrin, A., Gondet, B., Poulet, F., Berthé, M., Soufflot, A., Arvidson, R., Mangold, N., Mustard, J., Drossart, P.; the OMEGA Team. (2005) Mars surface diversity as revealed by the OMEGA/Mars Express observations. Science 307:1576-1581.

Bibring, J.-P., Langevin, Y., Mustard, J.F., Poulet, F., Arvidson, R., Gendrin, A., Gondet, B., Mangold, N., Pinet, P., Forget, F., Berthé, M., Bibring, J.P., Gendrin, A., Gomez, C., Gondet, B., Jouglet, D., Poulet, F., Soufflot, A., Vincendon, M., Combes, M., Drossart, P., Encrenaz, T., Fouchet, T., Merchiorri, R., Belluci, G., Altieri, F., Formisano, V., Capaccioni, F., Cerroni, P., Coradini, A., Fonti, S., Korablev, O., Kottsov, V., Ignatiev, N., Moroz, V., Titov, D., Zasova, L., Loiseau, D., Mangold, N., Pinet, P., Douté, S., Schmitt, B., Sotin, C., Hauber, E., Hoffmann, H., Jaumann, R., Keller, U., Arvidson, R., Mustard, J.F., Duxbury, T., Forget, F., and Neukum, G. (2006) Global mineralogical and aqueous Mars history derived from OMEGA/Mars Express data. Science 312:400-404.

Bishop, J.L., Dyar, M.D., Lane, M.D., and Banfield, J.F. (2005) Spectral identification of hydrated sulfates on Mars and comparison with acidic environments on Earth. International Journal of Astrobiology 3:275-285.

Blackhurst, R.L., Genge, M.J., Kearsley, A.T., and Grady, M.M. (2005) Cryptoendolithic alteration of Antarctic sandstones: pioneers or opportunists? J Geophys Res: Planets 110, doi:10.1029/2005JE002463.

Blamey, N.J.F., Parnell, J., McMahon, S., Mark, D.F., Tomkinson, T., Lee, M., Shivak, J., Izawa, M.R.M., Banerjee, N.R., and Flemming, R.L. (2015) Evidence for methane in martian meteorites. Nat Commun 6, doi:10.1038/ncomms8399.

Boetius, A., Anesio, A.M., Deming, J.W., Mikucki, J., and Rapp, J.Z. (2014) Microbial ecology of the cryosphere: sea ice and glacial habitats. Nat Rev Microbiol 13:677-690.

Borchers, M.R., Colwell, F.S., D’Angelo, G., Thurber, A.R., and Graw, M.F. (2015) Sediment interfaces: ecotones on a microbial scale [abstract B11I-0565]. In AGU Fall Meeting 2015, American Geophysical Union, Washington, DC.

Boston, P.J. (2010) Location, location, location! Lava caves on Mars for habitat, resources, and the search for life. Journal of Cosmology 12:3957-3979.

Boston, P.J., Ivanov, M.V., and McKay, C.P. (1992) On the possibility of chemosynthetic ecosystems in subsurface habitats on Mars. Icarus 95:300-308. 
Boston, P.J., Spilde, M.N., Northup, D.E., Melim, L.A., Soroka, D.S., Kleina, L.G., Lavoie, K.H., Hose, L.D., Mallory, L.M., Dahm, C.N., Crossey, L.J., and Schelble, R.T. (2001) Cave biosignature suites: microbes, minerals, and Mars. Astrobiology 1:25-55.

Boyce, J.M., Mouginis-Mark, P., and Garbeil, H. (2005) Ancient oceans in the northern lowlands of Mars: evidence from impact crater depth/diameter relationships. J Geophys Res: Planets 110, doi:10.1029/2004JE002328.

Brack, A. (2000) The exobiology exploration of Mars: a survey of the European approaches. Planet Space Sci 48:1023-1026.

Brack, A., Fitton, B., and Raulin, F. (1999) Exobiology in the Solar System and the Search for Life on Mars, Report from the ESA Exobiology Team Study 1997-1998, SP-1231, ESA Publications Division, ESTEC, Noordwijk, The Netherlands. Available online at http://www.esa.int/esapub/sp/sp1231/sp1231 .pdf

Bradley, D.C. (2015) Mineral evolution and Earth history. American Mineralogist 100, doi:10.2138/am-2015-5101.

Bradley, R.S., Vuille, M., Diaz, H.F., and Vergara, W. (2006) Threats to water supplies in the tropical Andes. Science 312: 1755-1756.

Brasser, R. (2013) The formation of Mars: building blocks and accretion time scale. Space Sci Rev 174:11-25.

Broz, P., Hauber, E., Wray, J.J., and Michael, G. (2017) Amazonian volcanism inside Valles Marineris on Mars. Earth Planet Sci Lett 473:122-130.

Buoro, M. and Carlson, S.M. (2014) Life-history syndromes: integrating dispersal through space and time. Ecol Lett 17: 756-767.

Burnham, A.D. and Berry, A.J. (2017) Formation of Hadean granites by melting of igneous crust. Nat Geosci 10:457-461.

Cabrol, N.A. and Grin, E. (1999) Distribution, classification, and ages of martian impact crater lakes. Icarus 142:160-172.

Cabrol, N.A. and Grin, E.A. (2001) Recent aqueous environments in martian impact craters: an astrobiological perspective. Icarus 154:98-112.

Cabrol, N.A. and Grin, E.A. (2005) Ancient and recent lakes on Mars. In Water on Mars and Life, edited by T. Tokano, Springer, Berlin, pp 235-259.

Cabrol, N.A. and Grin, E.A., editors. (2010) Lakes on Mars, Elsevier Science, Amsterdam.

Cabrol, N.A., Wettergreen, D., Warren-Rhodes, K., Grin, E.A., Moersch, J., Diaz, G.C., Cockell, C.S., Coppin, P., Demergasso, C., Dohm, J.M., Ernst, L., Fisher, G., Glasgow, J., Hardgrove, C., Hock, A.N., Jonak, D., Marinangeli, L., Minkley, E., Ori, G.G., Piatek, J., Pudenz, E., Smith, T., Stubbs, K., Thomas, G., Thompson, D., Waggoner, A., Wagner, M., Weinstein, S., and Wyatt, M. (2007a) Life in the Atacama: searching for life with rovers (science overview). $J$ Geophys Res: Biogeosciences 112, doi:10.1029/2006JG000298.

Cabrol, N.A., Grin, E.A., Kiss, K.T., Ács, E., Grigorszky, I., Szabò, K., Tóth, B., Fike, D.A., Hock, A.N., Demergasso, C., Escudero, L., Chong, G., Galleguillos, P., Grigsby, B.H., Zambrana Román, J., McKay, C.P., and Tambley, C. (2007b) Signatures of habitats and life in Earth's high-altitude lakes: clues to Noachian aqueous environments on Mars. In The Geology of Mars, edited by M. Chapman, Cambridge University Press, Cambridge, UK, pp 349-370.

Cabrol, N.A., Grin, E.A., and Hock, A.N. (2007c) Mitigation of environmental extremes as a possible indicator of extended habitat sustainability for lakes on early Mars. Proc SPIE 6694, doi:10.1117/12.731506.
Cabrol, N.A., Grin, E.A., Chong, G., Minkley, E., Hock, A.N., Yu, Y., Bebout, L., Fleming, E., Häder, D.P., Demergasso, C., Gibson, J., Escudero, L., Dorador, C., Lim, D., Woosley, C., Morris, R.L., Tambley, C., Gaete, V., Galvez, M.E., Smith, E., Uskin-Peate, I., Salazar, C., Dawidowicz, G., and Majerowicz, J. (2009) The high-lakes project. J Geophys Res: Biogeosciences 114, doi:10.1029/2008JG000818.

Cabrol, N.A., Feister, U., Häder, D.-P., Piazena, H., Grin, E.A., and Klein, A. (2014) Record solar UV irradiance in the tropical Andes. Front Environmen Sci 2, doi:10.3389/ fenvs.2014.00019.

Cabrol, N.A., Andersen, D., Bishop, J., Brown, A., Cady, S., Davila, A., DeVore, E., Ertem, G., Farmer, J., Grin, E.A., Gulick, V., Hinman, N., Moersch, J., Parro, V., Phillips, C., Quinn, R., Sobron, P., Sarrazin, P., Summers, D., Wettergreen, D.S., Wray, J., Zacny, K., Blake, D., Feister, U., Häder, D.-P., Leveille, R., Pollard, W., and Arvidson, R. (2015) Roadmap to biosignature exploration on Mars [abstract 7010]. In Astrobiology Science Conference, Lunar and Planetary Institute, Houston.

Cady, S.L. and Farmer, J.D. (1996) Fossilization processes in siliceous thermal springs: trends in preservation along thermal gradients. In Evolution of Hydrothermal Ecosystems on Earth (and Mars?), Ciba Foundation Symposium 202, John Wiley \& Sons, New York, pp 150-173.

Cady, S.L., Farmer, J.D., Grotzinger, J.P., Schopf, J.W., and Steele, A. (2003) Morphological biosignatures and the search for life on Mars. Astrobiology 3:351-368.

Candela, A., Thompson, D., Noe Dobrea, E., and Wettergreen, D. (2017) Planetary robotic exploration driven by science hypotheses for geologic mapping. In IEEE/RSJ International Conference on Intelligent Robots and Systems, Vancouver, Canada. Capone, D.G. and Hutchins, D.A. (2003) Microbial biogeochemistry of coastal upwelling regimes in a changing ocean. Nat Geosci 6:711-717.

Carr, M.H. (1996) Water on Mars, Oxford University Press, Oxford, UK.

Carr, M.H. (2012) The fluvial history of Mars. Philos Trans A Math Phys Eng Sci 370:2193-2215.

Carr, M.H. and Head, J.W. (2003) Oceans on Mars: an assessment of the observational evidence and possible fate. J Geophys Res 108, doi:10.1029/2002JE001963.

Carr, M.H. and Head, J.W. (2010) Geologic history of Mars. Earth Planet Sci Lett 294:185-203.

Carr, M.H. and Head, J.W. (2015) Martian surface/near-surface water inventory: sources, sinks, and changes with time. Geophys Res Lett 42:726-732.

Carter, J., Poulet, F., Bibring, J.P., Mangold, N., and Murchie, S. (2013) Hydrous minerals on Mars as seen by the CRISM and OMEGA imaging spectrometers: updated global view. J Geophys Res: Planets 118, doi:10.1029/2012JE004145.

Catling, D.C. and Kasting, J.F., editors. (2017) Atmospheric Evolution of Inhabited and Lifeless Worlds, Cambridge University Press, Cambridge, UK.

Cavosie, A.J., Valley, J.W., and Wilde, S.A. (2007) The oldest terrestrial mineral record: a review of 4400 to 4000 Ma detrital zircons from Jack Hills, Western Australia. In Developments in Precambrian Geology, edited by M.J. Van Kranendonk, R.H. Smithies, and V.C. Bennett, Elsevier, Amsterdam, pp 91-112.

Chapelle, F.H., O’Neill, K., Bradley, P.M., Methé, B.A., Ciufo, S.A., Knobel, L.L., and Lovley, D.R. (2002) A hydrogenbased subsurface microbial community dominated by methanogens. Nature 415:312-315. 
Chassefière, E., Langlais, B., Quesnel, Y., and Leblanc, F. (2013) The fate of early Mars' lost water: the role of serpentinization. J Geophys Res: Planets 118, doi:10.1002/jgre.20089.

Chastain, B.K. and Chevrier, V. (2007) Methane clathrate hydrates as a potential source for martian atmospheric methane. Planet Space Sci 55:1246-1256.

Chicarro, A.F. (2006) Mars Express science results and goals for the extended mission. Proceedings of the International Astronomical Union 2, doi:10.1017/S1743921307010903.

Chyba, C. and Sagan, C. (1992) Endogenous production, exogenous delivery and impact-shock synthesis of organic molecules: an inventory for the origins of life. Nature 355:125-132.

Clark, B.C., Baird, A.K., Rose, H.J., Jr., Toulmin, P., III, Keil, K., Castro, A.J., Kelliher, W.C., Rowe, C.D., and Evans, P.H. (1976) Inorganic analyses of martian surface samples at the Viking landing sites. Science 194:1283-1288.

Clifford, S.M. (1993) A model for the hydrologic and climatic behavior of water on Mars. J Geophys Res: Planets 98, doi: 10.1029/93je00225.

Clifford, S.M. and Parker, T.J. (2001) The evolution of the martian hydrosphere: implications for the fate of a primordial ocean and the current state of the northern plains. Icarus 154: 40-79.

Clobert, J., Baguette, M., and Benton, T.G. (2012) Dispersal ecology and evolution. In Dispersal Ecology and Evolution, edited by J. Clobert, Oxford University Press, Oxford, UK, doi:10.1093/acprof:oso/9780199608898.001.0001.

Cockell, C.S. (2010) Geomicrobiology beyond Earth: microbemineral interactions in space exploration and settlement. Trends Microbiol 18:308-314.

Cockell, C.S., Catling, D.C., Davis, W.L., Snook, K., Kepner, R.L., Lee, P., and McKay, C.P. (2000) The ultraviolet environment of Mars: biological implications past, present, and future. Icarus 146:343-359.

Cockell, C.S., Balme, M., Bridges, J.C., Davila, A., and Schwenzer, S.P. (2012) Uninhabited habitats on Mars. Icarus 217:184-193.

Cockell, C.S., Bush, T., Bryce, C., Direito, S., Fox-Powell, M., Harrison, J.P., Lammer, H., Landenmark, H., Martin-Torres, J., Nicholson, N., Noack, L., O’Malley-James, J., Payler, S.J., Rushby, A., Samuels, T., Schwendner, P., Wadsworth, J., and Zorzano, M.P. (2016) Habitability: a review. Astrobiology 16: 89-117.

Condie, K.C. and Kröner, A. (2008) When did plate tectonics begin? Evidence from the geologic record. In When Did Plate Tectonics Begin on Planet Earth? Geological Society of America Special Paper 440, edited by K.C. Condie and V. Pease, Geological Society of America, Boulder, CO, pp 281294.

Connerney, J.E.P., Acuña, M.H., Wasilewski, P.J., Ness, N.F., Reme, H., Mazelle, C., Vignes, D., Lin, R.P., Mitchell, D.L., and Cloutier, P.A. (1999) Magnetic lineations in the ancient crust of Mars. Science 284:794-798.

Costard, F., Séjourné, A., Kelfoun, K., Clifford, S., Lavigne, F., Di Pietro, I., and Bouley, S. (2017) Modeling tsunami propagation and the emplacement of thumbprint terrain in an early Mars ocean. J Geophys Res: Planets 122, doi:10.1002/ 2016JE005230.

Cousins, C.R. and Crawford, I.A. (2011) Volcano-ice interaction as a microbial habitat on Earth and Mars. Astrobiology 11:695-710.

Craddock, R.A. and Howard, A.D. (2002) The case for rainfall on a warm, wet early Mars. J Geophys Res: Planets 107, doi: 10.1029/2001JE001505.
Craddock, R.A. and Lorenz, R.D. (2017) The changing nature of rainfall during the early history of Mars. Icarus 293:172-179.

Dartnell, L.R. (2011) Ionizing radiation and life. Astrobiology 11:551-582.

Davila, A.F. and Schulze-Makuch, D. (2016) The last possible outposts for life on Mars. Astrobiology 16:159-168.

Davila, A.F., Hawes, I., Ascaso, C., and Wierzchos, J. (2013) Salt deliquescence drives photosynthesis in the hyperarid Atacama Desert. Environ Microbiol Rep 5:583-587.

de Hon, R.A. (2010) Hydrologic provinces of Mars: physiographic controls on drainage and ponding. In Lakes on Mars, edited by N.A. Cabrol and E.A. Grin, Elsevier Science, Amsterdam, pp 69-89.

Demergasso, C., Dorador, C., Meneses, D., Blamey, J., Cabrol, N., Escudero, L., and Chong, G. (2010) Prokaryotic diversity pattern in high-altitude ecosystems of the Chilean Altiplano. $J$ Geophys Res: Biogeosciences 115, doi:10.1029/2008JG000836.

Des Marais, D.J. (2010) Exploring Mars for evidence of habitable environments and life. Proc Am Philos Soc 154:402421.

Di Achille, G. and Hynek, B.M. (2010) Ancient ocean on Mars supported by global distribution of deltas and valleys. Nat Geosci 3:459-463.

Djokic, T., Van Kranendonk, M.J., Campbell, K.A., Walter, M.R., and Ward, C.R. (2017) Earliest signs of life on land preserved in ca. 3.5 Ga hot spring deposits. Nat Commun 8, doi:10.1038/ncomms15263.

Dodd, M.S., Papineau, D., Grenne, T., Slack, J.F., Rittner, M., Pirajno, F., O’Neil, J., and Little, C.T.S. (2017) Evidence for early life in Earth's oldest hydrothermal vent precipitates. Nature 543:60-64.

Dohm, J.M. and Maruyama, S. (2015) Habitable trinity. Geoscience Frontiers 6:95-101.

Dohm, J.M., Ferris, J.C., Baker, V.R., Anderson, R.C., Hare, T.M., Strom, R.G., Barlow, N.G., Tanaka, K.L., Klemaszewski, J.E., and Scott, D.H. (2001) Ancient drainage basin of the Tharsis Region, Mars: potential source for outflow channel systems and putative oceans or paleolakes. $J$ Geophys Res 106, doi:10.1029/2000JE001468.

Dohm, J.M., Williams, J.-P., Anderson, R.C., Ruiz, J., McGuire, P.C., Komatsu, G., Davila, A.F., Ferris, J.C., SchulzeMakuch, D., Baker, V.R., Boynton, W.V., Fairén, A.G., Hare, T.M., Miyamoto, H., Tanaka, K.L., and Wheelock, S.J. (2009a) New evidence for a magmatic influence on the origin of Valles Marineris, Mars. Journal of Volcanology and Geothermal Research 185:12-27.

Dohm, J.M., Baker, V.R., Boynton, W.V., Fairén, A.G., Ferris, J.C., Finch, M., Furfaro, R., Hare, T.M., Janes, D.M., Kargel, J.S., Karunatillake, S., Keller, J., Kerry, K., Kim, K.J., Komatsu, G., Mahaney, W.C., Schulze-Makuch, D., Marinangeli, L., Ori, G.G., Ruiz, J., and Wheelock, S.J. (2009b) GRS evidence and the possibility of paleooceans on Mars. Planet Space Sci 57:664-684.

Ebrahimi, A.N. and Or, D. (2014) Microbial dispersal in unsaturated porous media: characteristics of motile bacterial cell motions in unsaturated angular pore networks. Water Resour Res 50:7406-7429.

Edwards, K.J., Wheat, C.G., and Sylvan, J.B. (2011) Under the sea: microbial life in volcanic oceanic crust. Nat Rev Microbiol 9:703-712.

Edwards, K.J., Fisher, A.T., and Wheat, C.G. (2012) The deep subsurface biosphere in igneous ocean crust: frontier habitats for microbiological exploration. Front Microbiol 3, doi: 10.3389/fmicb.2012.00008. 
Ehlmann, B.L. and Edwards, C.S. (2014) Mineralogy of the martian surface. Annu Rev Earth Planet Sci 42:291-315.

Ehlmann, B.L., Mustard, J.F., Murchie, S.L., Poulet, F., Bishop, J.L., Brown, A.J., Calvin, W.M., Clark, R.N., Des Marais, D.J., Milliken, R.E., Roach, L.H., Roush, T.L., Swayze, G.A., and Wray, J.J. (2008) Orbital identification of carbonatebearing rocks on Mars. Science 322:1828-1832.

Ehlmann, B.L., Mustard, J.F., and Murchie, S.L. (2010) Geologic setting of serpentine deposits on Mars. Geophys Res Lett 37, doi:10.1029/2010GL042596.

Ehlmann, B.L., Anderson, F.S., Andrews-Hanna, J., Catling, D.C., Christensen, P.R., Cohen, B.A., Dressing, C.D., Edwards, C.S., Elkins-Tanton, L.T., Farley, K.A., Fassett, C.I., Fischer, W.W., Fraeman, A.A., Golombek, M.P., Hamilton, V.E., Hayes, A.G., Herd, C.D.K., Horgan, B., Hu, R., Jakosky, B.M., Johnson, J.R., Kasting, J.F., Kerber, L., Kinch, K.M., Kite, E.S., Knutson, H.A., Lunine, J.I., Mahaffy, P.R., Mangold, N., McCubbin, F.M., Mustard, J.F., Niles, P.B., Quantin-Nataf, C., Rice, M.S., Stack, K.M., Stevenson, D.J., Stewart, S.T., Toplis, M.J., Usui, T., Weiss, B.P., Werner, S.C., Wordsworth, R.D., Wray, J.J., Yingst, R.A., Yung, Y.L., and Zahnle, K.J. (2016) The sustainability of habitability on terrestrial planets: insights, questions, and needed measurements from Mars for understanding the evolution of Earth-like worlds. J Geophys Res: Planets 121, doi:10.1002/ 2016JE005134.

Ehrenfreund, P. and Cami, J. (2010) Cosmic carbon chemistry: from the interstellar medium to the early Earth. Cold Spring Harb Perspect Biol 2, doi:10.1101/cshperspect.a002097.

Ehresmann, B., Hassler, D.M., Zeitlin, C., Guo, J., Köhler, J., Wimmer-Schweingruber, R.F., Appel, J.K., Brinza, D.E., Rafkin, S.C., Böttcher, S.I., Burmeister, S., Lohf, H., Martin, C., Böhm, E., Matthiä, D., and Reitz, G. (2014) Charged particle spectra measured during the transit to Mars with the Mars Science Laboratory Radiation Assessment Detector (MSL/RAD). Life Sci Space Res 10:29-37.

Elkins-Tanton, L.T. (2008) Linked magma ocean solidification and atmospheric growth for Earth and Mars. Earth Planet Sci Lett 271:181-191.

Elkins-Tanton, L.T. (2011) Formation of early water oceans on rocky planets. Astrophys Space Sci 332:359-364.

Erkaev, N.V., Lammer, H., Elkins-Tanton, L.T., Stökl, A., Odert, P., Marcq, E., Dorfi, E.A., Kislyakova, K.G., Kulikov, Y.N., Leitzinger, M., and Güdel, M. (2014) Escape of the martian protoatmosphere and initial water inventory. Planet Space Sci 98:106-119.

Ertem, G., Ertem, M.C., McKay, C.P., and Hazen, R.M. (2017) Shielding biomolecules from effects of radiation by Mars analogue minerals and soils. International Journal of Astrobiology 16:282-285.

Etiope, G., Ehlmann, B.L., and Schoell, M. (2013) Low temperature production and exhalation of methane from serpentinized rocks on Earth: a potential analog for methane production on Mars. Icarus 224:276-285.

Fairén, A.G., Dohm, J.M., Baker, V.R., de Pablo, M.A., Ruiz, J., Ferris, J.C., and Anderson, R.C. (2003) Episodic flood inundations of the northern plains of Mars. Icarus 165:53-67.

Fairén, A.G., Dohm, J.M., Uceda, E.R., Rodríguez, A.P., Baker, V.R., Fernández-Remolar, D., Schulze-Makuch, D., and Amils, R. (2005) Prime candidate sites for astrobiological exploration through the hydrogeological history of Mars. Planet Space Sci 53:1355-1375.

Fairén, A.G., Davila, A.F., Lim, D., Bramall, N., Bonaccorsi, R., Zavaleta, J., Uceda, E.R., Stoker, C., Wierzchos, J.,
Dohm, J.M., Amils, R., Andersen, D., and McKay, C.P. (2010) Astrobiology through the ages of Mars: the study of terrestrial analogues to understand the habitability of Mars. Astrobiology 10:821-843.

Fairén, A.G, Dohm, J.M., Rodríguez, J.A.P., Uceda, E.R., Kargel, J., Soare, R., Cleaves, H.J., Oehler, D., SchulzeMakuch, D., Essefi, E., Banks, M.E., Komatsu, G., Fink, W., Robbins, S., Yan, J., Miyamoto, H., Maruyama, S., and Baker, V.R. (2016) The Argyre Region as a prime target for in situ astrobiological exploration of Mars. Astrobiology 16: 143-158.

Farmer, J.D. (1996) Hydrothermal systems on Mars: an assessment of present evidence. In Evolution of Hydrothermal Ecosystems on Earth (and Mars?), Ciba Foundation Symposium 202, John Wiley \& Sons, New York, pp 273-299.

Farmer, J.D. and Des Marais, D.J. (1999) Exploring for a record of ancient martian life. J Geophys Res: Planets 104, doi: 10.1029/1998je000540.

Fassett, C.I. and Head, J.W. (2008) Valley network-fed, openbasin lakes on Mars: distribution and implications for Noachian surface and subsurface hydrology. Icarus 198:37-56.

Fassett, C.I. and Head, J.W. (2011) Sequence and timing of conditions on early Mars. Icarus 211:1204-1214.

Feldman, W.C., Boynton, W.V., Tokar, R.L., Prettyman, T.H., Gasnault, O., Squyres, S.W., Elphic, R.C., Lawrence, D.J., Lawson, S.L., Maurice, S., McKinney, G.W., Moore, K.R., and Reedy, R.C. (2002) Global distribution of neutrons from Mars: results from Mars Odyssey. Science 297:75-78.

Fierer, N. (2008) Microbial biogeography: patterns in microbial diversity across space and time. In Accessing Uncultivated Microorganisms: From the Environment to Organisms and Genomes and Back, edited by K. Zengler, ASM Press, Washington, DC, pp 95-115.

Fisher, A.T., Mankoff, K.D., Tulaczyk, S.M., Tyler, S.W., and Foley, N. (2015) High geothermal heat flux measured below the West Antarctic Ice Sheet. Sci Adv 1, doi:10.1126/ sciadv. 1500093.

Fisher, C., Takai, K., and Le Bris, N. (2007) Hydrothermal vent ecosystems. Oceanography 20:14-23.

Fontaneto, D. and Hortal, J. (2012) Microbial biogeography: is everything small everywhere? Microbial Ecological Theory: Current Perspectives, edited by L.A. Ogilvie and P.R. Hirsch, Caister Academic, Norfolk, UK, pp 87-98.

Freissinet, C., Glavin, D.P., Mahaffy, P.R., Miller, K.E., Eigenbrode, J.L., Summons, R.E., Brunner, A.E., Buch, A., Szopa, C., Archer, P.D., Jr., Franz, H.B., Atreya, S.K., Brinckerhoff, W.B., Cabane, M., Coll, P., Conrad, P.G., Des Marais, D.J., Dworkin, J.P., Fairén, A.G., François, P., Grotzinger, J.P., Kashyap, S., ten Kate, I.L., Leshin, L.A., Malespin, C.A., Martin, M.G., Martin-Torres, J.F., McAdam, A.C., Ming, D.W., Navarro-González, R., Pavlov, A.A., Prats, B.D., Squyres, S.W., Steele, A., Stern, J.C., Sumner, D.Y., Sutter, B., Zorzano, M.-P.; MSL Science Team. (2015) Organic molecules in the Sheepbed Mudstone, Gale Crater, Mars. J Geophys Res: Planets 120:495-514.

Frey, H. (2008) Ages of very large impact basins on Mars: implications for the Late Heavy Bombardment in the inner Solar System. Geophys Res Lett 35, doi:10.1029/2008GL033515.

Frey, H. and Schultz, R.A. (1988) Large impact basins and the mega-impact origin for the crustal dichotomy on Mars. Geophys Res Lett 15:229-232.

Frey, H.V. (2003) Buried impact basins and the earliest history of Mars [abstract 3104]. In 35 th Lunar and Planetary Science Confeerence, Lunar and Planetary Institute, Houston. 
Frey, H.V. (2006) Impact constraints on the age and origin of the lowlands of Mars. Geophys Res Lett 33, doi:10.1029/ 2005 GL024484.

Gaidos, E. and Selsis, F. (2007) From protoplanets to protolife: the emergence and maintenance of life. In Protostars and Planets V, edited by B. Reipurth, D. Jewitt, and K. Keil, University of Arizona Press, Tuscon, pp 929-944.

Gendrin, A., Mangold, N., Bibring, J.P., Langevin, Y., Gondet, B., Poulet, F., Bonello, G., Quantin, C., Mustard, J., Arvidson, R., and LeMouélic, S. (2005) Sulfates in martian layered terrains: the OMEGA/Mars Express view. Science 307:1587-1591.

Ghiorse, W.C. and Wilson, J.T. (1988) Microbial ecology of the terrestrial subsurface. Adv Appl Microbiol 33:107-172.

Gilbert, W. (1986) Origin of life: the RNA world. Nature 319, doi:10.1038/319618a0.

Golombek, M.P., Arvidson, R.E., Bell, J.F., III, Christensen, P.R., Crisp, J.A., Crumpler, L.S., Ehlmann, B.L., Fergason, R.L., Grant, J.A., Greeley, R., Haldemann, A.F., Kass, D.M., Parker, T.J., Schofield, J.T., Squyres, S.W., and Zurek, R.W. (2005) Assessment of Mars Exploration Rover landing site predictions. Nature 436:44-48.

Gómez, F., Mateo-Martí, E., Prieto-Ballesteros, O., MartínGago, J., and Amils, R. (2010) Protection of chemolithoautotrophic bacteria exposed to simulated Mars environmental conditions. Icarus 209:482-487.

Gómez, F., Rodríguez-Manfredi, J.A., Rodríguez, N., FernándezSampedro, M., Caballero-Castrejón, F.J., and Amils, R. (2012) Habitability: where to look for life? Halophilic habitats: Earth analogs to study Mars habitability. Planet Space Sci 68:48-55.

Grassi, D., Formisano, V., Forget, F., Fiorenza, C., Ignatiev, N.I., Maturilli, A., and Zasova, L.V. (2007) The martian atmosphere in the region of Hellas Basin as observed by the Planetary Fourier Spectrometer (PFS-MEX). Planet Space Sci 55:1346-1357.

Greeley, R. and Spudis, P.D. (1981) Volcanism on Mars. Rev Geophys 19:13-41.

Greenberger, R.N., Mustard, J.F., Cloutis, E.A., Pratt, L.M., Sauer, P.E., Mann, P., Turner, K., Dyar, M.D., and Bish, D.L. (2015) Serpentinization, iron oxidation, and aqueous conditions in an ophiolite: implications for hydrogen production and habitability on Mars. Earth Planet Sci Lett 416:21-34.

Greenwood, J.P. and Blake, R.E. (2006) Evidence for an acidic ocean on Mars from phosphorus geochemistry of martian soils and rocks. Geology 34:953-956.

Griebler, C. and Lueders, T. (2009) Microbial biodiversity in groundwater ecosystems. Freshw Biol 54:649-677.

Groffman, P.M. and Bohlen, P.J. (1999) Soil and sediment biodiversity. Bioscience 49:139-148.

Grott, M., Morschhauser, A., Breuer, D., and Hauber, E. (2011) Volcanic outgassing of $\mathrm{CO}_{2}$ and $\mathrm{H}_{2} \mathrm{O}$ on Mars. Earth Planet Sci Lett 308:391-400.

Grotzinger, J.P. (2014) Habitability, taphonomy, and the search for organic carbon on Mars. Science 343:386-387.

Grotzinger, J.P., Summer, D.Y., Kah, L.C., Stack, K., Gupta, S., Edgar, L., Rubin, D., Lewis, K., Schieber J., Mangold, N., et al., MSL Science Team. (2014) A habitable fluvio-lacustrine environment at Yellowknife Bay, Gale Crater, Mars. Science 343; http://dx.doi.org/10.1126.science.1242777.

Grotzinger, J.P., Crisp, J.A., and Vasavada, A.R. (2015a) Curiosity's mission of exploration at Gale Crater, Mars. Elements 11:19-26.

Grotzinger, J.P., Gupta, S., Malin, M.C., Rubin, D.M., Schieber, J., Siebach, K., Sumner, D.Y., Stack, K.M., Vasavada, A.R., Arvidson, R.E., Calef, F., Edgar, L., Fischer, W.F., Grant,
J.A., Griffes, J., Kah, L.C., Lamb, M.P., Lewis, K.W., Mangold, N., Minitti, M.E., Palucis, M., Rice, M., Williams, R.M.E., Yingst, R.A., Blake, D., Blaney, D., Conrad, P., Crisp, J., Dietrich, W.E., Dromart, G., Edgett, K.S., Ewing, R.C., Gellert, R., Hurowitz, J.A., Kocurek, G., Mahaffy, P., McBride, M.J., McLennan, S.M., Mischna, M., Ming, D., Milliken, R., Newsom, H., Oehler, D., Parker, T.J., Vaniman, D., Wiens, R.C., and Wilson, S.A. (2015b) Deposition, exhumation, and paleoclimate of an ancient lake deposit, Gale Crater, Mars. Science 350, doi:10.1126/science.aac7575.

Gulick, V.C. (1998) Magmatic intrusions and a hydrothermal origin for fluvial valleys on Mars. J Geophys Res 103, doi: 10.1029/98JE01321.

Gulick, V.C. and Baker, V.R. (1989) Fluvial valleys and martian palaeoclimates. Nature 341:514-516.

Gulick, V.C., Tyler, D., McKay, C.P., and Haberle, R.M. (1997) Episodic ocean-induced $\mathrm{CO}_{2}$ greenhouse on Mars: implications for fluvial valley formation. Icarus 130:68-86.

Haberle, R.M, McKay, C.P., Schaeffer, J., Cabrol, N.A., Grin, E.A., Zent, A.P., and Quinn, R. (2001) On the possibility of liquid water on present-day Mars. J Geophys Res 106, doi: 10.1029/2000JE001360.

Häder, D.-P. and Gao, K. (2015) Interactions of anthropogenic stress factors on marine phytoplankton. Front Environmen Sci 3, doi:10.3389/fenvs.2015.00014.

Halevy, I. and Head, J.W., III. (2014) Episodic warming of early Mars by punctuated volcanism. Nat Geosci 7:865-868.

Harrison, J.P., Gheeraert, N., Tsigelnitskiy, D., and Cockell, C.S. (2013) The limits for life under multiple extremes. Trends Microbiol 21:204-212.

Harrison, K.P. and Grimm, R.E. (2008) Multiple flooding events in martian outflow channels. $J$ Geophys Res: Planets 113, doi:10.1029/2007JE002951.

Hassler, D.M., Zeitlin, C., Wimmer-Schweingruber, R.F., Ehresmann, B., Rafkin, S., Eigenbrode, J.L., Brinza, D.E., Weigle, G., Böttcher, S., Böhm, E., Burmeister, S., Guo, J., Köhler, J., Martin, C., Reitz, G., Cucinotta, F.A., Kim, M.H., Grinspoon, D., Bullock, M.A., Posner, A., Gómez-Elvira, J., Vasavada, A., Grotzinger, J.P.; MSL Science Team. (2014) Mars' surface radiation environment measured with the Mars Science Laboratory's Curiosity rover. Science 343, doi:10.1126/science. 1244797.

Hauber, E., Brož, P., Jagert, F., Jodowski, P., and Platz, T. (2011) Very recent and wide-spread basaltic volcanism on Mars. Geophys Res Lett 38, doi:10.1029/2011GL047310.

Hays, L.E., Graham, H.V., Des Marais, D.J., Hausrath, E.M., Horgan, B., McCollom, T.M., Parenteau, M.N., PotterMcIntyre, S.L., Williams, A.J., and Lynch, K.L. (2017) Biosignature preservation and detection in Mars analog environments. Astrobiology 17:363-400.

Hazen, R.M. (2012) Geochemical origins of life. In Fundamentals of Geobiology, edited by A.H. Knoll, D.E. Canfield, and K.O. Konhauser, Wiley-Blackwell, Hoboken, NJ, pp 315-332.

Hazen, R.M., Sverjensky, D.A., Azzolini, D., Bish, D.L., Elmore, S.C., Hinnov, L., and Milliken, R.E. (2013) Clay mineral evolution. Am Mineral 98:2007-2029.

Head, J.W. (2007) The geology of Mars: new insights and outstanding questions. In The Geology of Mars: Evidence from Earth-Based Analogs, edited by M. Chapman, Cambridge University Press, Cambridge, UK, pp 1-46.

Head, J.W. and Wilson, L. (2002) Mars: a review and synthesis of general environments and geological settings of magma$\mathrm{H}_{2} \mathrm{O}$ interactions. Geol Soc Spec Publ 202:27-57. 
Head, J.W., III, Kreslavsky, M., Hiesinger, H., Ivanov, M., Pratt, S., Seibert, N., Smith, D.E., and Zuber, M.T. (1998) Oceans in the past history of Mars: tests for their presence using Mars Orbiter Laser Altimeter (MOLA) data. Geophys Res Lett 25:4401-4404.

Head, J.W., Mustard, J., Kreslavsky, M., Milliken, R., and Marchant, D. (2003) Recent ice ages on Mars. Nature 426: 797-802.

Head, J.W., Marchant, D.R., Dickson, J.L., Kress, A.M., and Baker, D.M. (2010) Northern mid-latitude glaciation in the Late Amazonian period of Mars: criteria for the recognition of debris-covered glacier and valley glacier landsystem deposits. Earth Planet Sci Lett 294:306-320.

Hiesinger, H. and Head, J.W., III. (2002) Topography and morphology of the Argyre Basin, Mars: implications for its geologic and hydrologic history. Planet Space Sci 50:939981.

Hock, A.N., Cabrol, N.A., Dohm, J.M., Piatek, J., WarrenRhodes, K., Weinstein, S., Wettergreen, D.S., Grin, E.A., Moersch, J., Cockell, C.S., Coppin, P., Ernst, L., Fisher, G., Hardgrove, C., Marinangeli, L., Minkley, E., Ori, G.G., Waggoner, A., Wyatt, M., Smith, T., Thompson, D., Wagner, M., Jonak, D., Stubbs, K., Thomas, G., Pudenz, E., and Glasgow, J. (2007) Life in the Atacama: a scoring system for habitability and the robotic exploration for life. J Geophys Res: Biogeosciences 112, doi:10.1029/2006JG000321.

Hofmann, B.A., Farmer, J.D., von Blanckenburg, F., and Fallick, A.E. (2008) Subsurface filamentous fabrics: an evaluation of origins based on morphological and geochemical criteria, with implications for exopaleontology. Astrobiology 8:87-117.

Hofmann, H.J., Grey, K., Hickman, A.H., and Thorpe, R.I. (1999) Origin of 3.45 Ga coniform stromatolites in Warrawoona Group, Western Australia. Geol Soc Am Bull 111: 1256-1262.

Hoshino, T., Toki, T., Ijiri, A., Morono, Y., Machiyama, H., Ashi, J., Okamura, K., and Inagaki, F. (2017) Atribacteria from the subseafloor sedimentary biosphere disperse to the hydrosphere through submarine mud volcanoes. Front $\mathrm{Mi}$ crobiol 8, doi:10.3389/fmicb.2017.01135.

Hovius, N., Lea-Cox, A., and Turowski, J.M. (2008) Recent volcano-ice interaction and outburst flooding in a Mars polar cap re-entrant. Icarus 197:24-38.

Howard, A.D., Moore, J.M., and Irwin, R.P. (2005) An intense terminal epoch of widespread fluvial activity on early Mars: 1. Valley network incision and associated deposits. J Geophys Res: Planets 110, doi:10.1029/2005JE002459.

Hu, R., Kass, D.M., Ehlmann, B.L., and Yung, Y.L. (2015) Tracing the fate of carbon and the atmospheric evolution of Mars. Nat Commun 6, doi:10.1038/ncomms10003.

Hynek, B.M. and Phillips, R.J. (2003) New data reveal mature, integrated drainage systems on Mars indicative of past precipitation. Geology 31:757-760.

Inada, A., Richardson, M.I., McConnochie, T.H., Strausberg, M.J., Wang, H., and Bell, J.F., III. (2007) High-resolution atmospheric observations by the Mars Odyssey Thermal Emission Imaging System. Icarus 192:378-395.

Irwin, R.P., Howard, A.D., and Maxwell, T.A. (2004) Geomorphology of Ma'adim Vallis, Mars, and associated paleolake basins. J Geophys Res: Planets 109, doi:10.1029/ 2004JE002287.

Ishii, T., Kawaichi, S., Nakagawa, H., Hashimoto, K., and Nakamura, R. (2015) From chemolithoautotrophs to electrolithoautotrophs: $\mathrm{CO}_{2}$ fixation by $\mathrm{Fe}(\mathrm{II})$-oxidizing bacteria coupled with direct uptake of electrons from solid electron sources. Front Microbiol 6, doi:10.3389/fmicb.2015.00994.

Jakosky, B.M. and Phillips, R.J. (2001) Mars' volatile and climate history. Nature 412:237-244.

Jakosky, B.M. and Shock, E.L. (1998) The biological potential of Mars, the early Earth, and Europa. J Geophys Res 103, doi: 10.1029/98JE01892.

Jakosky, B.M., Slipski, M., Benna, M., Mahaffy, P., Elrod, M., Yelle, R., Stone, S., and Alsaeed, N. (2017) Mars' atmospheric history derived from upper-atmosphere measurements of ${ }^{38} \mathrm{Ar} /{ }^{36} \mathrm{Ar}$. Science 355:1408-1410.

Jansson, J.K. and Taş, N. (2014) The microbial ecology of permafrost. Nat Rev Microbiol 12:414-425.

Jenkins, D.G., Brescacin, C.R., Duxbury, C.V., Elliott, J.A., Evans, J.A., Grablow, K.R., Hillegass, M., Lyon, B.N., Metzger, G.A., Olandese, M.L., Pepe, D., Silvers, G.A., Suresch, H.N., Thompson, T.N., Trexler, C.M., Williams, G.E., Williams, N.C., and Williams, S.E. (2007) Does size matter for dispersal distance? Global Ecology and Biogeography 16:415-425.

Jepsen, S.M., Priscu, J.C., Grimm, R.E., and Bullock, M.A. (2007) The potential for lithoautotrophic life on Mars: application to shallow interfacial water environments. Astrobiology 7:342-354.

Jones, A.A. and Bennett, P.C. (2017) Mineral ecology: surface specific colonization and geochemical drivers of biofilm accumulation, composition, and phylogeny. Front Microbiol 8, doi:10.3389/fmicb.2017.00491.

Jones, E.G., Lineweaver, C.H., and Clarke, J.D. (2011) An extensive phase space for the potential martian biosphere. Astrobiology 11:1017-1033.

Jungbluth, S.P., Bowers, R.M., Lin, H.-t., Cowen, J.P., and Rappé, M.S. (2016) Novel microbial assemblages inhabiting crustal fluids within Mid-Ocean Ridge flank subsurface basalt. Nature 10, doi:10.1038/ismej.2015.248.

Kahre, M.A., Vines, S.K., Haberle, R.M., and Hollingsworth, J.L. (2013) The early martian atmosphere: investigating the role of the dust cycle in the possible maintenance of two stable climate states. J Geophys Res: Planets 118, doi:10.1002/ jgre.20099.

Kargel, J.S. (2006) Enceladus: cosmic gymnast, volatile miniworld. Science 311:1389-1391.

Kargel, J.S., Baker, V.R., Beget, J.E., Lockwood, J.F., Pewe, T.L., Shaw, J., and Strom, R.G. (1995) Evidence of ancient continental glaciation in the martian northern plains. $J$ Geophys Res 100, doi:10.1029/94JE02447.

Kargel, J.S., Furfaro, R., Prieto-Ballesteros, O., Rodriguez, J.A.P., Montgomery, D.R., Gillespie, A.R., Marion, G.M., and Wood, S.E. (2007) Martian hydrogeology sustained by thermally insulating gas and salt hydrates. Geology 35:975-978.

Kelly, L.C., Cockell, C.S., Thorsteinsson, T., Marteinsson, V., and Stevenson, J. (2014) Pioneer microbial communities of the Fimmvorduhals Lava Flow, Eyjafjallajokull, Iceland. Microb Ecol 68:504-518.

Kite, E.S., Williams, J.P., Lucas, A., and Aharonson, O. (2014) No title. Nat Geosci 75:335-339.

Klein, C., Beukes, N.J., and Schopf, J.W. (1987) Filamentous microfossils in the Early Proterozoic Transvaal Supergroup: their morphology, significance, and paleoenvironmental setting. Precambrian Res 36:81-94.

Knoll, A.H. (2009) The coevolution of life and environments. Rend Lincei Sci Fis Nat 20:301-306.

Knoll, A.H. and Grotzinger, J. (2006) Water on Mars and the prospect of martian life. Elements 2:169-173. 
Knoll, A.H., Carr, M., Clark, B., Des Marais, D.J., Farmer, J.D., Fischer, W.W., Grotzinger, J.P., McLennan, S.M., Malin, M., Schröder, C., Squyres, S., Tosca, N.J., and Wdowiak, T. (2005) An astrobiological perspective on Meridiani Planum. Earth Planet Sci Lett 240:179-189.

Korenaga, J. (2013) Initiation and evolution of plate tectonics on Earth: theories and observations. Annu Rev Earth Planet Sci 41:117-151.

Kreisch, C.D., O'Sullivan, J.A., Arvidson, R.E., Politte, D.V., He, L., Stein, N.T., Finkel, J., Guinness, E.A., Wolff, M.J., and Lapôtre, M.G.A. (2017) Regularization of Mars Reconnaissance Orbiter CRISM along-track oversampled hyperspectral imaging observations of Mars. Icarus 282:136151.

Kreslavsky, M.A. and Head, J.W. (2002) Fate of outflow channel effluents in the northern lowlands of Mars: the Vastitas Borealis Formation as a sublimation residue from frozen ponded bodies of water. J Geophys Res 107, doi: 10.1029/2001JE001831.

Kreslavsky, M.A. and Head, J.W. (2005) Mars at very low obliquity: atmospheric collapse and the fate of volatiles. Geophys Res Lett 32, doi:10.1029/2005GL022645.

Kruse, F.A., Taranik, J.V., Coolbaugh, M., Michaels, J., Littlefield, E.F., Calvin, W.M., and Martini, B.A. (2011) Effect of reduced spatial resolution on mineral mapping using imaging spectrometry-examples using Hyperspectral Infrared Imager (HyspIRI)-simulated data. Remote Sensing 3:15841602.

Kurokawa, H., Sato, M., Ushioda, M., Matsuyama, T., Moriwaki, R., Dohm, J.M., and Usui, T. (2014) Evolution of water reservoirs on Mars: constraints from hydrogen isotopes in martian meteorites. Earth Planet Sci Lett 394:179-185.

Lahav, N., White, D., and Chang, S. (1978) Peptide formation in the prebiotic era: thermal condensation of glycine in fluctuating clay environments. Science 201:67-69.

Lanz, J.K. and Saric, M.B. (2009) Cone fields in SW Elysium Planitia: hydrothermal venting on Mars? J Geophys Res: Planets 114, doi:10.1029/2008JE003209.

Lasaga, A.C., Holland, H.D., and Dwyer, M.J. (1971) Primordial oil slick. Science 174:53-55.

Laskar, J., Levrard, B., and Mustard, J.F. (2002) Orbital forcing of the martian polar layered deposits. Nature 419:375-377.

Lazcano, A. and Miller, S.L. (1996) The origin and early evolution of life: prebiotic chemistry, the pre-RNA world, and time. Cell 85:793-798.

Leavitt, P.R., Vinebrooke, R.D., Donald, D.B., Smol, J.P., and Schindler, D.W. (1997) Past ultraviolet radiation environments in lakes derived from fossil pigments. Nature 388:457459.

Leone, G., Tackley, P.J., Gerya, T.V., May, D.A., and Zhu, G. (2014) Three-dimensional simulations of the southern polar giant impact hypothesis for the origin of the martian dichotomy. Geophys Res Lett 41:8736-8743.

Levin, G.V. and Straat, P.A. (2016) The case for extant life on Mars and its possible detection by the Viking labeled release experiment. Astrobiology 16:798-810.

Levine, J.S. and Summers, M.E. (2008) Sulfur dioxide and the production of sulfuric acid on present-day and early Mars: implications for the lack of detected carbonates on the surface. In Third International Workshop on the Mars Atmosphere: Modeling and Observations, Lunar and Planetary Institute, Houston, p 9016.

Levrard, B., Forget, F., Montmessin, F., and Laskar, J. (2004) Recent ice-rich deposits formed at high latitudes on Mars by sublimation of unstable equatorial ice during low obliquity. Nature 431, doi:10.1038/nature03006.1.

Levy, J.S., Goudge, T.A., Head, J.W., III, and Fassett, C.I. (2017) Candidate volcanic and impact-induced ice depressions on Mars. Icarus 285:185-194.

Lingenfelter, R.E. and Schubert, G. (1973) Evidence for convection in planetary interiors from first-order topography. Moon 7:172-180.

Lucchitta, B.K. (2001) Antarctic ice streams and outflow channels on Mars. Geophys Res Lett 28:403-406.

Lucchitta, B.K. (2010) Lakes in Valles Marineris. In Lakes on Mars, edited by N.A. Cabrol and E.A. Grin, Elsevier Science, Amsterdam, pp 111-161.

Luo, W., Cang, X., and Howard, A.D. (2017) New martian valley network volume estimate consistent with ancient ocean and warm and wet climate. Nat Commun 8, doi:10.1038/ ncomms 15766 .

Lutz, S., Anesio, A.M., Edwards, A., and Benning, L.G. (2017) Linking microbial diversity and functionality of Arctic glacial surface habitats. Environ Microbiol 19:551-565.

Lyons, T.W., Reinhard, C.T., and Planavsky, N.J. (2014) The rise of oxygen in Earth's early ocean and atmosphere. Nature 506:307-315.

Malin, M.C. and Edgett, K.S. (1999) Oceans or seas in the martian northern lowlands: high resolution imaging tests of proposed shorelines. Geophys Res Lett 26:3049-3052.

Marinova, M.M., Aharonson, O., and Asphaug, E.I. (2008) Mega-impact formation of the Mars hemispheric dichotomy. Nature 453:1216-1219.

Martin, W., Baross, J., Kelley, D., and Russel, M. (2008) Hydrothermal vents and the origin of life. Nat Rev 6:805-814.

Martiny, J.B., Bohannan, B.J., Brown, J.H., Colwell, R.K., Fuhrman, J.A., Green, J.L., Horner-Devine, M.C., Kane, M., Krumins, J.A., Kuske, C.R., Morin, P.J., Naeem, S., Ovreås, L., Reysenbach, A.L., Smith, V.H., and Staley, J.T. (2006) Microbial biogeography: putting microorganisms on the map. Nat Rev Microbiol 4:102-112.

Maruyama, S., Santosh, M., and Zhao, D. (2007) Superplume, supercontinent, and post-perovskite: mantle dynamics and anti-plate tectonics on the core-mantle boundary. Gondwana Res 11:7-37.

McCabe, R.M., Hickey, B.M., Kudela, R.M., Lefebvre, K.A., Adams, N.G., Bill, B.D, Gulland, F.M.D., Thomson, R.E., Cochlan, W.P., and Trainer, V.L. (2016) An unprecedented coastwide toxic algal bloom linked to anomalous ocean conditions. Geophys Res Lett 43:10366-10376.

McCollom, T.M. (2013) Miller-Urey and beyond: what have we learned about prebiotic organic synthesis reactions in the past 60 years? Annu Rev Earth Planet Sci 41:207-229.

McEwen, A.S., Malin, M.C., Carr, M.H., and Hartmann, W.K. (1999) Voluminous volcanism on early Mars revealed in Valles Marineris. Nature 397:584-586.

McEwen, A.S., Hansen, C.J., Delamere, W.A., Eliason, E.M., Herkenhoff, K.E., Keszthelyi, L., Gulick, V.C., Kirk, R.L., Mellon, M.T., Grant, J.A., Thomas, N., Weitz, C.M., Squyres, S.W., Bridges, N.T., Murchie, S.L., Seelos, F., Seelos, K., Okubo, C.H., Milazzo, M.P., Tornabene, L.L., Jaeger, W.L., Byrne, S., Russell, P.S., Griffes, J.L., Martínez-Alonso, S., Davatzes, A., Chuang, F.C., Thomson, B.J., Fishbaugh, K.E., Dundas, C.M., Kolb, K.J., Banks, M.E., and Wray, J.J. (2007) A closer look at water-related geologic activity on Mars. Science 317:1706-1709.

McEwen, A.S., Lujendra, O., Dundas, C.M., Mattson, S.S., Byrne, S., Wray, J.J., Cull, S.C., Murchie, S.L., Thomas, N., 
and Gulick, V.C. (2011) Seasonal flows on warm martian slopes. Science 333:740-743.

McGill, G.E. and Dimitriou, A.M. (1990) Origin of the martian global dichotomy by crustal thinning in the Late Noachian or Early Hesperian. J Geophys Res 95:12595-12605.

McKay, C., Stoker, C.R., Glass, B.J., Davé, A.I., Davila, A.F., Heldmann, J.L., Marinova, M.M., Fairén, A.G., Quinn, R.C., Zacny, K.A., Paulsen, G., Smith, P.H., Parro, V., Andersen, D.T., Hecht, M.H., Lacelle, D., and Pollard, W.H. (2013) The Icebreaker Life mission to Mars: a search for biomolecular evidence for life. Astrobiology 13:334-354.

McKay, C.P. (2010) An origin of life on Mars. Cold Spring Harb Perspect Biol doi:10.1101/cshperspect.a003509.

McKay, C.P. and Stoker, C.R. (1989) The early environment and its evolution on Mars: implication for life. Rev Geophys 27:189-214.

McKenzie, D. and Nimmo, F. (1999) The generation of martian floods by the melting of ground ice above dykes. Nature 397: 231-233.

MEPAG NEX-SAG Report. (2015) Report from the Next Orbiter Science Analysis Group (NEX-SAG), chaired by B. Campbell and R. Zurek. Available online at https://mepag .jpl.nasa.gov/reports/NEX-SAG_draft_v29_FINAL.pdf

Meyer, J.L., Jaekel, U., Tully, B.J., Glazer, B.T, Wheat, C.G., Lin, H.-T., Hsieh, C.-C., Cowen, J.P., Hulme, S.M., Girguis, P.R., and Hubera, J.A. (2016) A distinct and active bacterial community in cold oxygenated fluids circulating beneath the western flank of the Mid-Atlantic Ridge. Sci Rep 6, doi: $10.1038 /$ srep22541.

Meyer, M.A. and Schulte, M.D. (2014) The Mars 2020 mission: the next step forward in Mars exploration [abstract \#P24A01]. In AGU Fall Meeting 2014, American Geophysical Union, Washington, DC.

Michaelian, K. (2011) Thermodynamic dissipation theory for the origin of life. Earth System Dynamics 1:37-51.

Michalski, J.R. and Bleacher, J.E. (2013) Supervolcanoes within an ancient volcanic province in Arabia Terra, Mars. Nature 502:47-52.

Michalski, J.R., Noe Dobrea, E.Z., Niles, P.B., and Cuadros, J. (2017) Ancient hydrothermal seafloor deposits in Eridania Basin on Mars. Nat Commun 8, doi:10.1038/ncomms 15978.

Miller, S.L. and Urey, H.C. (1959) Organic compound synthesis on the primitive Earth. Science 130:245-251.

Mischna, M.A., Richardson, M.I., Wilson, R.J., and McCleese, D.J. (2003) On the orbital forcing of martian water and $\mathrm{CO}_{2}$ cycles: a general circulation model study with simplified volatile schemes. J Geophys Res: Planets 108, doi:10.1029/ 2003JE002051.

Mischna, M.A., Baker, V., Milliken, R., Richardson, M., and Lee, C. (2013) Effects of obliquity and water vapor/trace gas greenhouses in the early martian climate. $J$ Geophys Res: Planets 118, doi:10.1002/jgre.20054.

Montgomery, D.R. and Gillespie, A. (2005) Formation of martian outflow channels by catastrophic dewatering of evaporite deposits. Geology 33:625-628.

Montross, S., Skidmore, M., Christner, B., Samyn, D., Tison, J.-L., Lorrain, R., Doyle, S., and Fitzsimons, S. (2013) Debris-rich basal ice as a microbial habitat, Taylor Glacier, Antarctica. Geomicrobiol J 31:76-81.

Moore, J.M. and Wilhelms, D.E. (2001) Hellas as a possible site of ancient ice-covered lakes on Mars. Icarus 154:258-276.

Mouginis-Mark, P.J. and Christensen, P.R. (2005) New observations of volcanic features on Mars from the THEMIS instrument. J Geophys Res: Planets 110, doi:10.1029/2005JE002421.
Mouginis-Mark, P.J., Wilson, L., Head, J.W., III, Brown, S.H., Hall, J.L., and Sullivan, K.D. (1984) Elysium Planitia, Mars: regional geology, volcanology, and evidence for volcanoground ice interactions. Earth Moon Planets 30:149-173.

Mouginot, J., Pommerol, A., Beck, P., Kofman, W., and Clifford, S.M. (2012) Dielectric map of the martian northern hemisphere and the nature of plain filling materials. Geophys Res Lett 39, doi:10.1029/2011GL050286.

Mumma, M.J., Villanueva, G.L., Novak, R.E., Hewagama, T., Bonev, B.P., DiSanti, M.A., Mandell, A.M., and Smith, M.D. (2009) Strong release of methane on Mars in northern summer 2003. Science 323:1041-1045.

Murchie, S.L., Mustard, J.F., Ehlmann, B.L., Milliken, R.E., Bishop, J.L., McKeown, N.K., Noe Dobrea, E.Z., Seelos, F.P., Buczkowski, D.L., Wiseman, S.M., Arvidson, R.E., Wray, J.J., Swayze, G., Clark, R.N., Des Marais, D.J., McEwen, A.S., and Bibring, J.-P. (2009) A synthesis of martian aqueous mineralogy after 1 Mars year of observations from the Mars Reconnaissance Orbiter. J Geophys Res: Planets 114, doi:10.1029/2009JE003342.

Mustard, J., Adler, M., Allwood, A., Bass, D., Beaty, D., Bell, J., Brinckerhoff, W., Carr, M., Des Marais, D.J., Drake, B., Edgett, K.S., Eigenbrode, J., Elkins-Tanton, L.T., Grant, J.A., Milkovich, S.M., Ming, D., Moore, C., Murchie, S., Onstott, T.C., Ruff, S.W., Sephton, M.A., Steele, A., and Treiman, A. (2013) Appendix to the Report of the Mars 2020 Science Definition Team, Mars Exploration Program Analysis Group (MEPAG), pp 155-205. Available online at http://mepag.jpl .nasa.gov/reports/MEP/Mars_2020_SDT_Report_Appendix .pdf

Navarro-González, R., Rainey, F.A., Molina, P., Bagaley, D.R., Hollen, B.J., de la Rosa, J., Small, A.M., Quinn, R.C., Grunthaner, F.J., Cáceres, L., Gomez-Silva, B., and McKay, CP. (2003) Mars-like soils in the Atacama Desert, Chile, and the dry limit of microbial life. Science 302:1018-1021.

Nemergut, D.R., Costello, E.K., Hamady, M., Lozupone, C., Jiang, L., Schmidt, S.K., Fierer, N., Townsend, A.R., Cleveland, C.C., Stanish, L., and Knight, R. (2011) Global patterns in the biogeography of bacterial taxa. Environ Microbiol 13:135-144.

Nemergut, D.R., Schmidt, S.K., Fukami, T., O’Neill, S.P., Bilinski, T.M., Stanish, L.F., Knelman, J.E., Darcy, J.L., Lynch, R.C., Wickey, P., and Ferrneberg, S. (2013) Patterns and processes of microbial community assembly. Microbiol Mol Biol Rev 77:342-356.

Neukum, G., Jaumann, R., Hoffmann, H., Hauber, E., Head, J.W., Basilevsky, A.T., Ivanov, B.A., Werner, S.C., van Gasselt, S., Murray, J.B., McCord, T.; HRSC Co-investigator Team. (2004) Recent and episodic volcanic and glacial activity on Mars revealed by the High Resolution Stereo Camera. Nature 432:971-979.

Newsom, H.E. (2010) Heated lakes on Mars. In Lakes on Mars, edited by N.A. Cabrol and E.A. Grin, Elsevier Science, Amsterdam, pp 91-110.

Niles, P.B., Beaty, D., Hays, L., Bass, D., Bell, M.S., Bleacher, J., Cabrol, N.A., Conrad, P., Eppler, D., Hamilton, V., Head, J., Kahre, M., Levy, J., Lyons, T., Rafkin, S., Rice, J., and Rice, M. (2017) Scientific investigations associated with the human exploration of Mars in the next 35 years [abstract 8167]. In Planetary Science Vision 2050 Workshop, Lunar and Planetary Institute, Houston.

Nimmo, F., Hart, S.D., Korycansky, D.G., and Agnor, C.B. (2008) Implications of an impact origin for the martian hemispheric dichotomy. Nature 453:1220-1223. 
Nisbet, E.G. and Fowler, C.M.R. (2013) The early history of life. In Treatise on Geochemistry, $2^{\text {nd }}$ ed., edited by H.D. Holland and K.K. Turekian, Elsevier Science, Amsterdam, doi:10.1016/B978-0-08-095975-7.00801-9.

Noffke, N. (2009) The criteria for the biogeneicity of microbially induced sedimentary structures (MISS) in Archean and younger, sandy deposits. Earth-Science Reviews 96:173-180.

Noffke, N., Beukes, N., Gutzmer, J., and Hazen, R. (2006) Spatial and temporal distribution of microbially induced sedimentary structures: a case study from siliciclastic storm deposits of the $2.9 \mathrm{Ga}$ Witwatersrand Supergroup, South Africa. Precambrian Res 146:35-44.

Noffke, N., Christian, D., Wacey, D., and Hazen, R.M. (2013) Microbially induced sedimentary structures recording an ancient ecosystem in the $c a$. 3.48 billion-year-old Dresser Formation, Pilbara, Western Australia. Astrobiology 13:11031124.

Nutman, A.P., Bennett, V.C., Friend, C.R.L., Van Kranendonk, M.J., and Chivas, A.R. (2016) Rapid emergence of life shown by discovery of 3,700-million-year-old microbial structures. Nature 537:535-538.

Oehler, D.Z. and Etiope, G. (2017) Methane seepage on Mars: where to look and why. Astrobiology 17, doi:10.1089/ ast.2017.1657.

Osinski, G.R. and Pierazzo, E. (2012) Impact cratering: processes and products. In Impact Cratering: Processes and Products, edited by G.R. Osinski and E. Pierazzo, John Wiley \& Sons, New York, pp 1-20.

Osinski, G.R., Tornabene, L.L., Banerjee, N.R., Cockell, C.S., Flemming, R., Izawa, M.R.M., McCutcheon, J., Parnell, J., Preston, L.J., Pickersgill, A.E., Pontefract, A., Sapers, H.M., and Southam, G. (2013) Impact-generated hydrothermal systems on Earth and Mars. Icarus 224:347-363.

Papke, R.T. and Ward, D.M. (2004) The importance of physical isolation to microbial diversification. FEMS Microbiol Ecol 48:293-303.

Parker, T.J., Saunders, R.S., and Schneeberger, D.M. (1989) Transitional morphology in West Deuteronilus Mensae, Mars: implications for modification of the lowland/upland boundary. Icarus 82:111-145.

Parker, T.J., Gorsline, D.S., Saunders, R.S., Pieri, D.C, and Schneeberger, D.M. (1993) Coastal geomorphology of the martian northern plains. J Geophys Res 98, doi:10.1029/ 93JE00618.

Parkes, R.J., Cragg, B.A., Bale, S.J., Getlifff, J.M., Goodman, K., Rochelle, P.A., Fry, J.C., Weightman, A.J., and Harvey, S.M. (1994) Deep bacterial biosphere in Pacific Ocean sediments. Nature 371:410-413.

Pavlov, A.A., Vasilyev, G., Ostryakov, V.M., Pavlov, A.K., and Mahaffy, P. (2012) Degradation of the organic molecules in the shallow subsurface of Mars due to irradiation by cosmic rays. Geophys Res Lett 39, doi:10.1029/2012GL052166.

Pergola, P. and Cipolla, V. (2016) Mission architecture for Mars exploration based on small satellites and planetary drones. International Journal of Intelligent Unmanned Systems 4: 142-162.

Perron, J.T., Mitrovica, J.X., Manga, M., Matsuyama, I., and Richards, M.A. (2007) Evidence for an ancient martian ocean in the topography of deformed shorelines. Nature 447:840-843.

Petro, C., Starnawski, P., Schramm, A., and Kjeldsen, K.U. (2017) Microbial community assembly in marine sediments. Aquat Microb Ecol 79:177-195.

Phillips, M.S., Moersch, J.E., and Cabrol, N.A. (2017) Thresholds of detectability for habitable environments in the
Altiplano of Chile with implications for Mars exploration [abstract 3373]. In Astrobiology Science Conference, Lunar and Planetary Institute, Houston.

Pirajno, F. (2009) Hydrothermal Processes and Mineral Systems, Springer, Dordrecht, The Netherlands.

Pirajno, F. (2015) Intracontinental anorogenic alkaline magmatism and carbonatites, associated mineral systems and the mantle plume connection. Gondwana Res 27:1181-1216.

Plescia, J.B. (2003) Cerberus Fossae, Elysium, Mars: a source for lava and water. Icarus 164:79-95.

Postawko, S.E. and Kuhn, W.R. (1986) Effect of the greenhouse gases $\left(\mathrm{CO}_{2}, \mathrm{H}_{2} \mathrm{O}, \mathrm{SO}_{2}\right)$ on martian paleoclimate. J Geophys Res: Solid Earth 91:431-438.

Poulet, F., Mangold, N., Loizeau, D., Bibring, J.-P.P., Langevin, Y., Michalski, J., and Gondet, B. (2008) Abundance of minerals in the phyllosilicate-rich units on Mars. Astron Astrophys 487, doi:10.1051/0004-6361:200810150.

Preston, L.J. and Dartnell, L.R. (2014) Planetary habitability: lessons learned from terrestrial analogues. International Journal of Astrobiology 13:81-98.

Quinn, R.C., Martucci, H.F.H., Miller, S.R., Bryson, C.E., Grunthaner, F.J., and Grunthaner, P.J. (2013) Perchlorate radiolysis on Mars and the origin of martian soil reactivity. Astrobiology 13:515-520.

Rabatel, A., Francou, B., Soruco, A., Gomez, J., Cáceres, B., Ceballos, J.L., Basantes, R., Vuille, M., Sicart, J.-E., Huggel, C., Scheel, M., Lejeune, Y., Arnaud, Y., Collet, M., Condom, T., Consoli, G., Favier, V., Jomelli, V., Galarraga, R., Ginot, P., Maisincho, L., Mendoza, J., Ménégoz, M., Ramirez, E., Ribstein, P., Suarez, W., Villacis, M., and Wagnon, P. (2013) Current state of glaciers in the tropical Andes: a multi-century perspective on glacier evolution and climate change. Cryosphere 7:81-102.

Rahmati, A., Larson, D.E., Cravens, T.E., Lillis, R.J., Dunn, P.A., Halekas, J.S., Connerney, J.E., Eparvier, F.G., Thiemann, E.M.B., and Jakosky, B.M. (2015) MAVEN insights into oxygen pickup ions at Mars. Geophys Res Lett 42:88708876.

Ramirez, R.M., Kopparapu, R., Zugger, M.E., Robinson, T.D., Freedman, R., and Kasting, J.F. (2013) Warming early Mars with $\mathrm{CO}_{2}$ and $\mathrm{H}_{2}$. Nat Geosci 7:59-63.

Reese, C.C., Orth, C.P., and Solomatov, V.S. (2011) Impact megadomes and the origin of the martian crustal dichotomy. Icarus 213:433-442.

Reith, F. (2011) Life in the deep subsurface. Geology 39:287288.

Rempfert, K.R., Miller, H.M., Bompard, N., Nothaft, D., Matter, J.M., Kelemen, P., Fierer, N., and Templeton, A.S. (2017) Geological and geochemical controls on subsurface microbial life in the Samail Ophiolite, Oman. Front Microbiol 8, doi: 10.3389/fmicb.2017.00056.

Retallack, G.J. (2014) Paleosols and paleoenvironments of early Mars. Geology 42:755-758.

Rhode, S.C., Pawlowski, M., and Tollrian, R. (2001) The impact of ultraviolet radiation on the vertical distribution of zooplankton of the genus Daphnia. Nature 412:69-72.

Robbins, S.J., Di Achille, G., and Hynek, B.M. (2011) The volcanic history of Mars: high-resolution crater-based studies of the calderas of 20 volcanoes. Icarus 211:1179-1203.

Rodríguez, A. and van Bergen, M.J. (2015) Volcanic hydrothermal systems as potential analogues of martian sulphaterich terrains. Netherlands Journal of Geosciences 92:153-169.

Rodriguez, J.A.P., Platz, T., Gulick, V., Baker, V.R., Fairén, A.G., Kargel, J., Yan, J., Miyamoto, H., and Glines, N. (2015) 
Did the martian outflow channels mostly form during the Amazonian period? Icarus 257:387-395.

Rodriguez, J.A.P., Fairén, A.G., Tanaka, K.L., Zarroca, M., Linares, R., Platz, T., Komatsu, G., Miyamoto, H., Kargel, J.S., Yan, J., Gulick, V., Higuchi, K., Baker, V.R., and Glines, N. (2016) Tsunami waves extensively resurfaced the shorelines of an early martian ocean. Sci Rep 6, doi:10.1038/ srep25106.

Röling, W.F.M., Aerts, J.W., Patty, C.H.L., Loes ten Kate, I., Ehrenfreund, P., and Direito, S.O.L. (2015) The significance of microbe-mineral-biomarker interactions in the detection of life on Mars and beyond. Astrobiology 15:492-507.

Rontó, G., Bérces, A., Lammer, H., Cockell, C.S., MolinaCuberos, G.J., Patel, M.R., and Selsis, F. (2003) Solar UV irradiation conditions on the surface of Mars. Photochem Photobiol 77:34-40.

Rosing, M.T. and Frei, R. (2004) U-rich Archaean sea-floor sediments from Greenland-indications of $>3700$ Ma oxygenic photosynthesis. Earth Planet Sci Lett 217:237-244.

Roussel, E.G., Bonavita, M.-A.C., Querellou, J., Cragg, B.A., Webster, G., Prieur, D., and Parkes, J.R. (2008) Extending the sub-sea-floor biosphere. Science 320, doi:10.1126/science. 1154545.

Ruff, S.W. and Farmer, J.D. (2016) Silica deposits on Mars with features resembling hot spring biosignatures at El Tatio in Chile. Nat Commun 7, doi:10.1038/ncomms13554.

Ruff, S.W., Niles, P.B., Alfano, F., and Clarke, A.B. (2014) Evidence for a Noachian-aged ephemeral lake in Gusev Crater, Mars. Geology 42:359-362.

Rummel, J.D., Beaty, D.W., Jones, M.A., Bakermans, C., Barlow, N.G., Boston, P.J., Chevrier, V.F., Clark, B.C., de Vera, J.P., Gough, R.V., Hallsworth, J.E., Head, J.W., Hipkin, V.J., Kieft, T.L., McEwen, A.S., Mellon, M.T., Mikucki, J.A., Nicholson, W.L., Omelon, C.R., Peterson, R., Roden, E.E., Sherwood Lollar, B., Tanaka, K.L., Viola, D., and Wray, J.J. (2014) A new analysis of Mars 'Special Regions': findings of the Second MEPAG Special Regions Science Analysis Group (SR-SAG2). Astrobiology 14:887-968.

Russell, M.J., Nitschke, W., and Branscomb, E. (2013) The inevitable journey to being. Philos Trans $R$ Soc Lond B Biol Sci 368, doi:10.1098/rstb.2012.0254.

Russell, P.S. and Head, J.W., III. (2007) The martian hydrologic system: multiple recharge centers at large volcanic provinces and the contribution of snowmelt to outflow channel activity. Planet Space Sci 55:315-332.

Santosh, M. (2010) Supercontinent tectonics and biogeochemical cycle: a matter of 'life and death.' Geoscience Frontiers $1: 21-30$.

Santosh, M., Arai, T., and Maruyama, S. (2017) Hadean Earth and primordial continents: the cradle of prebiotic life. Geoscience Frontiers 8:309-327.

Schopf, J.W. (2006) Fossil evidence of Archaean life. Philos Trans R Soc Lond B Biol Sci 361, doi:10.1098/rstb.2006 .1834.

Schopf, J.W., Kudryavtsev, A.B., Czaja, A.D., and Tripathi, A.B. (2007) Evidence of Archean life: stromatolites and microfossils. Precambrian Res 158:141-155.

Schulte, M., Blake, D., Hoehler, T., and McCollom, T. (2006) Serpentinization and its implications for life on the early Earth and Mars. Astrobiology 6:364-376.

Schulze-Makuch, D., Irwin, L.N., Lipps, J.H., Lemone, D., Dohm, J.M., and Fairén, A.G. (2005) Scenarios for the evolution of life on Mars. J Geophys Res 110, doi:10.1029/ 2005JE002430.
Schulze-Makuch, D., Dohm, J.M., Fan, C., Fairén, A.G., Rodriguez, J.A.P., Baker, V.R., and Fink, W. (2007) Exploration of hydrothermal targets on Mars. Icarus 189:308-324.

Schulze-Makuch, D., Fairén, A.G., and Davila, A.F. (2008) The case for life on Mars. International Journal of Astrobiology 7: 117-141.

Schulze-Makuch, D., Schulze-Makuch, A., and Houtkooper, J. (2015) The physical, chemical and physiological limits of life. Life 5:1472-1486.

Schwenzer, S.P., Abramov, O., Allen, C.C., Clifford, S.M., Cockell, C.S., Filiberto, J., Kring, D.A., Lasue, J., McGovern, P.J., Newsom, H.E., Treiman, A.H., Vaniman, D.T., and Wiens, R.C. (2012) Puncturing Mars: how impact craters interact with the martian cryosphere. Earth Planet Sci Lett 335-336:9-17.

Seckbach, J., Oren, A., and Stan-Lotter, H., editors. (2013) Polyextremophiles, Springer, Dordrecht, The Netherlands.

Segura, T.L., Toon, O.B., Colaprete, A., and Zahnle, K. (2002) Environmental effects of large impacts on Mars. Science 298: 1977-1980.

Shapiro, R. (2000) A replicator was not involved in the origin of Life. IUBMB Life 49:173-176.

Shock, E.L. (1992) Chemical environments of submarine hydrothermal systems. Orig Life Evol Biosph 22:67-107.

Shock, E.L. (1993) Hydrothermal dehydration of aqueous organic compounds. Geochim Cosmochim Acta 57:3341-3349.

Sleep, N.H. (1994) Martian plate tectonics. J Geophys Res 99, doi:10.1029/94JE00216.

Sleep, N.H. (2010) The Hadean-Archaean environment. Cold Spring Harb Perspect Biol doi:10.1101/cshperspect.a002527.

Sleep, N.H. and Lowe, D.R. (2014) Physics of crustal fracturing and chert dike formation triggered by asteroid impact, $\sim 3.26$ $\mathrm{Ga}$, Barberton Greenstone Belt, South Africa. Geochem Geophys Geosyst 15:1054-1070.

Smith, T., Thompson, D.R., Wettergreen, D.S., Cabrol, N.A., Warren-Rhodes, K.A., and Weinstein, S.J. (2007) Life in the Atacama: science autonomy for improving data quality. $J$ Geophys Res: Biogeosciences 112, doi:10.1029/2006JG000315.

Solomon, S.C., Aharonson, O., Aurnou, J.M., Banerdt, W.B., Carr, M.H., Dombard, A.J., Frey, H.V., Golombek, M.P., Hauck, S.A., II, Head, J.W., III, Jakosky, B.M., Johnson, C.L., McGovern, P.J., Neumann, G.A., Phillips, R.J., Smith, D.E., and Zuber, M.T. (2005) New perspectives on ancient Mars. Science 307:1214-1220.

Stanley, S., Elkins-Tanton, L., Zuber, M.T., and Parmentier, E.M. (2008) Mars' paleomagnetic field as the result of a single-hemisphere dynamo. Science 321:1822-1825.

Stepinski, T.F. and Collier, M.L. (2004) Extraction of martian valley networks from digital topography. J Geophys Res: Planets 109, doi:10.1029/2004JE002269.

Stern, R.J. (2005) Evidence from ophiolites, blueschists, and ultrahigh-pressure metamorphic terranes that the modern episode of subduction tectonics began in Neoproterozoic time. Geology 33:557-560.

Steven, B., Léveillé, R., Pollard, W.H., and Whyte, L.G. (2006) Microbial ecology and biodiversity in permafrost. Extremophiles 10:259-267.

Stevens, T. (1997) Lithoautotrophy in the subsurface. FEMS Microbiol Rev 20:327-337.

Stoker, C.R., Cannon, H.N., Dunagan, S.E., Lemke, L.G., Glass, B.J., Miller, D., Gomez-Elvira, J., Davis, K., Zavaleta, J., Winterholler, A., Roman, M., Rodriguez-Manfredi, J.A., Bonaccorsi, R., Bell, M.S., Brown, A., Battler, M., Chen, B., Cooper, G., Davidson, M., Fernández-Remolar, D., Gonzales- 
Pastor, E., Heldmann, J.L., Martínez-Frías, J., Parro, V., Prieto-Ballesteros, O., Sutter, B., Schuerger, A.C., Schutt, J., and Rull, F. (2008) The 2005 MARTE robotic drilling experiment in Río Tinto, Spain: objectives, approach, and results of a simulated mission to search for life in the martian subsurface. Astrobiology 8:921-945.

Stuurman, C.M., Osinski, G.R., Holt, J.W., Levy, J.S., Brothers, T.C., Kerrigan, M., and Campbell, B.A. (2016) SHARAD detection and characterization of subsurface water ice deposits in Utopia Planitia, Mars. Geophys Res Lett 43:9484-9491.

Summons, R.E., Amend, J.P., Bish, D., Buik, R., Cody, G.D., Des Marais, D.J., Dromart G., Eigenbrode, J.L., Knoll, A.H., and Sumner, D.Y. (2011) Preservation of martian organic and environmental records: final report of the Mars Biosignature Working Group. Astrobiology 11:157-181.

Suosaari, E.P., Reid, R.P., Playford, P.E., Foster, J.S., Stolz, J.F., Casaburi, G., Hagan, P.D., Chirayath, V., Macintyre, I.G., Planavsky, N.J., and Eberli, G.P. (2016) New multiscale perspectives on the stromatolites of Shark Bay, Western Australia. Sci Rep 6, doi:10.1038/srep20557.

Świąder, A. (2014) Identification and visualisation of possible ancient ocean shoreline on Mars using submeter-resolution digital terrain models. Geologos 4:289-301.

Tanaka, K.L. (1986) The stratigraphy of Mars. J Geophys Res 91, doi:10.1029/JB091iB13p0E139.

Tao, Y. and Muller, J.P. (2016) A novel method for surface exploration: super-resolution restoration of Mars repeat-pass orbital imagery. Planet Space Sci 121:104-113.

Thompson, B.J. and Head, J.W., III. (2001) Utopia Basin, Mars: characterization of topography and morphology and assessment of the origin and evolution of basin internal structure. $J$ Geophys Res 106, doi:10.1029/2000JE001355.

Thompson, D.R., Wettergreen, D.S., and Calderóon Peralta, F.J. (2011) Autonomous science during large-scale robotic survey. Journal of Field Robotics 28:542-564.

Tian, F., Kasting, J.F., and Solomon, S.C. (2009) Thermal escape of carbon from the early martian atmosphere. Geophys Res Lett 36, doi:10.1029/2008GL036513.

Trainer, M.G., Pavlov, A.A., DeWitt, H.L., Jimenez, J.L., McKay, C.P., Toon, O.B., and Tolbert, M.A. (2006) Organic haze on Titan and the early Earth. Proc Natl Acad Sci USA 103:18035-18042.

Travis, B.J., Rosenberg, N.D., and Cuzzi, J.N. (2003) On the role of widespread subsurface convection in bringing liquid water close to Mars' surface. J Geophys Res 108, doi: 10.1029/2002JE001877.

Ushikubo, T., Kita, N.T., Cavosie, A.J., Wilde, S.A., Rudnick, R.L., and Valley, J.W. (2008) Lithium in Jack Hills zircons: evidence for extensive weathering of Earth's earliest crust. Earth Planet Sci Lett 272:666-676.

Vago, J., Gardini, B., Kminek, G., Baglioni, P., Gianfiglio, G., Santovincenzo, A., Bayón, S., and Van Winnendael, M. (2006) ExoMars: searching for life on the red planet. ESA Bulletin 126:16-23.

Vago, J.L., Westall, F., Pasteur Instrument Teams, Landing Site Selection Working Group, and Other Contributors. (2017) Habitability on early Mars and the search for biosignatures with the ExoMars rover. Astrobiology 17:471-510.

Van Kranendonk, M.J. (2011) Morphology as an indictor of biogenicity for 3.5-3.2 Ga fossil stromatolites from the Pilbara Craton, Western Australia. Lecture Notes in Earth Sciences 131:537-554.

Van Zuilen, M.A., Lepland, A., Teranes, J., Finarelli, J., Wahlen, M., and Arrhenius, G. (2003) Graphite and carbon- ates in the $3.8 \mathrm{Ga}$ old Isua supracrustal belt, Southern West Greenland. Precambrian Res 126:331-348.

Varnes, E.S., Jakosky, B.M., and McCollom, T.M. (2003) Biological potential of martian hydrothermal systems. Astrobiology 3:407-414.

Villanueva, G.L., Mumma, M.J., Novak, R.E., Kaufl, H.U., Hartogh, P., Encrenaz, T., Tokunaga, A., Khayat, A., and Smith, M.D. (2015) Strong water isotopic anomalies in the martian atmosphere: probing current and ancient reservoirs. Science 348:218-221.

Visscher, P.T. (1993) Marine hydrothermal systems and the origin of life: N.G. Holm (Editor). Kluwer Academic Publishers, Dordrecht, 1992, hardcover, 242 pp. ISBN 0-79232018-2. Mar Chem 42:254-255.

Wächtershäuser, G. (2006) From volcanic origins of chemoautotrophic life to bacteria, archaea and eukarya. Philos Trans $R$ Soc Lond B Biol Sci 361:1787-1808.

Wadsworth, J. and Cockell, C.S. (2017) Perchlorates on Mars enhance the bacteriocidal effects of UV light. Sci Rep 7, doi: 10.1038/s41598-017-04910-3.

Walker, J.J. and Pace, N.R. (2007) Endolithic microbial ecosystems. Annu Rev Microbiol 61:331-347.

Walter, M. and Des Marais, D.J. (1993) Preservation of biological information in thermal spring deposits: developing a strategy for the search for fossil life on Mars. Icarus 101:129-143.

Walter, M.R. (1996) Ancient hydrothermal ecosystems on Earth: a new palaeobiological frontier. In Evolution of Hydrothermal Ecosystems on Earth (and Mars?), Ciba Foundation Symposium 202, John Wiley \& Sons, New York, pp 112-130.

Walter, M.R., Buick, R., and Dunlop, J.S.R. (1980) Stromatolites 3,400-3,500 Myr old from the North Pole Area, Western Australia. Nature 284:443-445.

Walter, M.R., Grotzinger, J.P., and Schopf, J.W. (1992) Proterozoic stromatolites. In The Proterozoic Biosphere: A Multidisciplinary Study, Cambridge University Press, Cambridge, UK, pp 253-260.

Warren-Rhodes, K., Weinstein, S., Dohm, J., Piatek, J., Minkley, E., Hock, A., Cockell, C., Pane, D., Ernst, L.A., Fisher, G., Emani, S., Waggoner, A.S., Cabrol, N.A., Wettergreen, D.S., Apostolopoulos, D., Coppin, P., Grin, E., Diaz, C., Moersch, J., Oril, G.G., Smith, T., Stubbs, K., Thomas, G., Wagner, M., and Wyatt, M. (2007a) Searching for microbial life remotely: satellite-to-rover habitat mapping in the Atacama Desert, Chile. J Geophys Res: Biogeosciences 112, doi: 10.1029/2006JG000283.

Warren-Rhodes, K., Weinstein, S., Piatek, J.L., Dohm, J., Hock, A., Minkley, E., Pane, D., Ernst, L.A., Fisher, G., Emani, S., Waggoner, A.S., Cabrol, N.A., Wettergreen, D.S., Grin, E., Coppin, P., Diaz, C., Moersch, J., Oril, G.G., Smith, T., Stubbs, K., Thomas, G., Wagner, M., Wyatt, M., and Boyle, L.Ng. (2007b) Robotic ecological mapping: habitats and the search for life in the Atacama Desert. J Geophys Res: Biogeosciences 112, doi:10.1029/2006JG000301.

Warren-Rhodes, K.A., Rhodes, K.L., Pointing, S.B., Ewing, S.A., Lacap, D.C., Gómez-Silva, B., Amundson, R., Friedmann, I.E., and McKay, C.P. (2006) Hypolithic cyanobacteria, dry limit of photosynthesis, and microbial ecology in the hyperarid Atacama Desert. Microb Ecol 52:389-398.

Washington, J. (2000) The possible role of volcanic aquifers in prebiologic genesis of organic compounds and RNA. Orig Life Evol Biosph 30:53-79.

Watkins, J.A., Ehlmann, B.L., and Yin, A. (2015) Long-runout landslides and the long-lasting effects of early water activity on Mars. Geology 43:107-110. 
Watters, T.R., McGovern, P.J., and Irwin, R.P., III. (2007) Hemispheres apart: the crustal dichotomy on Mars. Annu Rev Earth Planet Sci 35:621-652.

Webster, C.R, Mahaffy, P.R., Atreya, S.K., Flesch, G.J., Mischna, M.A., Meslin, P.Y., Farley, K.A., Conrad, P.G., Christensen, L.E., Pavlov, A.A., Martín-Torres, J., Zorzano, M.P., McConnochie, T.H., Owen, T., Eigenbrode, J.L., Glavin, D.P., Steele, A., Malespin, C.A., Archer, P.D., Jr., Sutter, B., Coll, P., Freissinet, C., McKay, C.P., Moores, J.E., Schwenzer, S.P., Bridges, J.C., Navarro-González, R., Gellert, R., Lemmon, M.T.; MSL Science Team. (2015) Mars methane detection and variability at Gale Crater. Science 347: 415-417.

Werner, S.C. (2009) The global martian volcanic evolutionary history. Icarus 201:44-68.

Westall, F., de Ronde, C.E.J., Southam, G., Grassineau, N., Colas, M., Cockell, C., and Lammer, H. (2006) Implications of a 3.472-3.333 Gyr-old subaerial microbial mat from the Barberton Greenstone Belt, South Africa for the UV environmental conditions on the Early Earth. Philos Trans $R$ Soc Lond B Biol Sci 361:1857-1876.

Westall, F., Loizeau, D., Foucher, F., Bost, N., Betrand, M., Vago, J., and Kminek, G. (2013) Habitability on Mars from a microbial point of view. Astrobiology 13:887-897.

Wettergreen, D., Cabrol, N., Teza, J., Tompkins, P., Urmson, C., Verma, V., Wagner, M., and Whittaker, W. (2005) First experiments in the robotic investigation of life in the Atacama Desert of Chile. In Proceedings of the 2005 IEEE International Conference on Robotics and Automation, IEEE, Piscataway, NJ, doi:10.1109/ROBOT.2005.1570227.

Whitman, W.B., Coleman, D.C., and Wiebe, W.J. (1998) Prokaryotes: the unseen majority. Proc Natl Acad Sci USA 95: 6578-6583.

Wierzchos, J., Ascaso, C., and McKay, C.P. (2006) Endolithic cyanobacteria in halite rocks from the hyperarid core of the Atacama Desert. Astrobiology 6:415-422.

Wilhelms, D.E. and Squyres, S.W. (1984) The martian hemispheric dichotomy may be due to a giant impact. Nature 309: $138-140$

Williams, J.P., Dohm, J.M., Soare, R.S., Flahaut, J., Lopes, R.M.C., Pathare, A.V., Fairén, A.G., Schulze-Makuch, D., and Buczkowski, D.L. (2017) Long-lived volcanism within Argyre Basin, Mars. Icarus 293:8-26.

Wilson, S.A., Moore, J.M., Howard, A.D., and Wilhelms, D.E. (2010) Evidence for ancient lakes in the Hellas Region. In Lakes on Mars, edited by N.A. Cabrol and E.A. Grin, Elsevier Science, Amsterdam, pp 195-222.

Wise, D.U., Golombek, M.P., and Mcgill, G.E. (1979) Tectonic evolution of Mars. J Geophys Res 84, doi:10.1029/JB084iB14p07934.

Womack, A.M., Bohannan, B.J.M., and Green, J.L. (2010) Biodiversity and biogeography of the atmosphere. Philos Trans $R$ Soc Lond B Biol Sci 365:3645-3653.
Wordsworth, R.D. (2016) The climate of early Mars. Annu Rev Earth Planet Sci 44, doi:10.1146/annurev-earth-060115012355.

Wray, J.J., Murchie, S.M., Squyres, S.S., Seelos, F.P., Tornabene, L.L. (2009) Diverse aqueous environments on ancient Mars revealed in the southern highlands. Geology 37:10431046.

Wynn-Williams, D.D., Cabrol, N.A., Grin, E.A., Haberle, R.M., and Stoker, C.R. (2001) Brines in seepage channels as eluants for subsurface relict biomolecules on Mars? Astrobiology 1: 165-184.

Yanagawa, K., Ijiri, A., Breuker, A., Sakai, S., Miyoshi, Y., Kawagucci, S., Noguchi, T., Hirai, M., Schippers, A., Ishibashi, J.I., Takaki, Y., Sunamura, M., Urabe, T., Nunoura, T., and Takai, K. (2017) Defining boundaries for the distribution of microbial communities beneath the sediment-buried, hydrothermally active seafloor. ISME J 11:529-542.

Yang, D., Peng, S., Hartman, M.R., Gupton-Campolongo, T., Rice, E.J., Chang, A.K., Gu, Z., Lu, G.Q.M., and Luo, D. (2013) Enhanced transcription and translation in clay hydrogel and implications for early life evolution. Sci Rep 3, doi:10.1038/srep03165.

Yin, A. (2012) Structural analysis of the Valles Marineris fault zone: possible evidence for large-scale strike-slip faulting on Mars. Lithosphere 4:286-330.

Yung, Y.L., Nair, H., and Gerstell, M.F. (1997) $\mathrm{CO}_{2}$ greenhouse in the early martian atmosphere: $\mathrm{SO}_{2}$ inhibits condensation. Icarus 130:222-224.

Zacny, K., Paulsen, G., McKay, C.P., Glass, B., Davé, A., Davila, A.F., Marinova, M., Mellerowicz, B., Heldmann, J., Stoker, C., Cabrol, N., Hedlund, M., and Craft, J. (2013) Reaching $1 \mathrm{~m}$ deep on Mars: the Icebreaker drill. Astrobiology 13:1166-1198.

Zahnle, K., Schaefer, L., and Fegley, B. (2010) Earth's earliest atmospheres. Cold Spring Harb Perspect Biol doi:10.1101/ cshperspect.a004895.

Zeglin, L.H. (2015) Stream microbial diversity in response to environmental changes: review and synthesis of existing research. Front Microbiol 6, doi:10.3389/fmicb.2015.00454.

Zhong, S. and Zuber, M.T. (2001) Degree-1 mantle convection and the crustal dichotomy on Mars. Earth Planet Sci Lett 189: $75-84$.

Address correspondence to: Nathalie A. Cabrol

The SETI Institute Carl Sagan Center $189 \mathrm{~N}$ Bernardo Ave \#200

Mountain View, CA 94043

E-mail: Nathalie.A.Cabrol@nasa.govor ncabrol@seti.org

Submitted 29 August 2017 Accepted 27 November 2017 